This is a self-archived version of an original article. This version may differ from the original in pagination and typographic details.

Author(s): Stephenson, Kathleen Ann; Kuismin, Ari; Putnam, Linda L.; Sivunen, Anu

Title: Process studies of organizational space

Year: 2020

Version: Published version

Copyright: (c) Academy of Management, 2020

Rights: $C C B Y-N C-N D 4.0$

Rights url: https://creativecommons.org/licenses/by-nc-nd/4.0/

Please cite the original version:

Stephenson, K. A., Kuismin, A., Putnam, L. L., \& Sivunen, A. (2020). Process studies of organizational space. Academy of Management Annals, 14(2), 797-827.

https://doi.org/10.5465/annals.2018.0146 


\title{
PROCESS STUDIES OF ORGANIZATIONAL SPACE
}

\author{
KATHLEEN A. STEPHENSON ${ }^{1}$ \\ Vrije Universiteit Amsterdam and University of Liverpool Management School
}

\author{
ARI KUISMIN \\ Aalto University School of Business \\ LINDA L. PUTNAM \\ University of California, Santa Barbara
}

\author{
ANU SIVUNEN \\ University of Jyväskylä
}

\begin{abstract}
The past decade has experienced an increase in the number of studies on organizational space or where work occurs. A number of these studies challenge traditional views of organizational space as a fixed, physical workspace because researchers fail to account for the spatial dynamics that they observe. New technologies, shifting employee-employer relations, and burgeoning expectations of the contemporary workforce blur boundaries between home and work, connect people and things that historically could not be linked, and extend workspaces to nearly everywhere, not just office buildings. Research on these transformations calls for incorporating movement into the physicality of work. Thus, organizational scholars have turned to process studies as ways to examine the dynamic features that create and alter spatial arrangements. However, the rapidly growing work in this area lacks integration and theoretical development. To address these concerns, we review and classify the organizational literature that casts space as a process, that is, dynamically as movements, performances, flows, and changing routines. This review yields five orientations of organizational space scholarship that we label as developing, transitioning, imbricating, becoming, and constituting. We discuss these orientations, examine how they relate to key constructs of organizational space, and show how this work offers opportunities to theorizing about organizations.
\end{abstract}

Within organization and management studies, the research on space has moved from a fringe area to a pivotal concern for organizational theorizing. Organizational space refers to the built environments that emerge from organizational activities, objects, arrangements, and social practices ${ }^{2}$ (Beyes \& Steyaert, 2012; Cunliffe \& Luchman, 2013). This move has ushered in the treatment of space as both enabling and constraining actions rather than functioning as

We are grateful for Elizabeth George and her expert guidance through the development of this project, and Seton Beggs who helped us with the difficult task of visually representing space as a process.

${ }^{1}$ Corresponding author.

2 Thus, we do not examine studies of virtual spaces, platforms, or distributed environments (e.g., Saunders, Rutkowski, van Genuchten, Vogel, \& Molina Orrego, 2011) because they occur within or as an output of organizational spaces. a neutral, stable container (Dale \& Burrell, 2008; Taylor \& Spicer, 2007). It also crosses vital issues in management studies, for example, how space interfaces with strategic work (Hydle, 2015; Jarzabkowski, Burke, \& Spee, 2015; Lancione \& Clegg, 2013), how physical arrangements play a role in maintaining institutions (Siebert, Wilson, \& Hamilton, 2017), and how new working areas allow employees to implement organizational changes (Kellogg, 2009).

Organizational space is pivotal to studies of identity (Decker, 2014; de Vaujany \& Vaast, 2014; Liu \& Grey, 2017), roles (Halford \& Leonard, 2005), gender dynamics (Tyler \& Cohen, 2010; Wasserman \& Frenkel, 2011), leadership (Crevani, 2018a; Ropo, Sauer, \& Salovaara, 2013), entrepreneurship (Hjorth, 2005), relationships among coworkers (Khazanchi, Sprinkle, Masterson, \& Tong, 2018), and innovation (Furnari, 2014). Research also shows how organizational space influences formal and informal work 
interactions (Fayard \& Weeks, 2007; Hirst, 2011), fosters the development of trust (Nilsson \& Mattes, 2015; Sturdy, Schwarz, \& Spicer, 2006), shapes positions in governance (McNulty \& Stewart, 2015), embodies power relations (Hirst \& Humphreys, 2013; Zhang \& Spicer, 2014), and controls workers while offering opportunities for resistance (Barnes, 2007; Courpasson, Dany, \& Delbridge, 2017; Iedema, Rhodes, \& Scheers, 2006).

In addition, recent interest in organizational space examines the "processual and performative actions" that constitute it (Beyes \& Steyaert, 2012: 48) rather than treating it as "fixed, dead and immobile" (Taylor \& Spicer, 2007: 325). Before this shift, scholars conceived of organizational space as a stable, physical environment that managers and architects could design to achieve particular goals (Elsbach \& Pratt, 2007). However, this work neglected the inherent movement of space, including how individuals rearranged, extended, or repurposed space within a single day. In effect, recent research focuses on moment-to-moment processes of inhabiting and practicing organizational space as well as attending to spatial design.

Even though "process studies" of organizational space have existed for over a decade, the literature is widely dispersed, encompasses an array of different topics, and embraces divergent theoretical lenses. As of yet, scholars have not synthesized this growing body of work. Without such a review, it is difficult (1) to articulate what organizational space is and does, (2) to identify how process approaches build off each other and depart from more traditional thinking about space, and (3) to explicate how process approaches to space enact organization and organizing.

Addressing these challenges is essential because work is no longer limited to set office spaces, rather it is performed everywhere. This is evident as contemporary workspaces constantly shift from homes, to cafes, to coworking spaces, and during commutes. Consequently, scholars need to examine the material aspects of space in conjunction with the ongoing activities, practices, and work relationships of organizational processes.

The purpose of this review is to synthesize and integrate research on organizational space as a process, to bring conceptual coherence to this area and to suggest a direction for future studies. We do this in four steps. First, we show how scholars have moved from examining space as a physical container to investigating it as a changing and evolving process. Second, we offer a theoretically grounded typology of five process orientations-developing, transitioning, imbricating, becoming, and constituting-that researchers use in this area and that reveal different assumptions about space and organizing. Third, we identify and elaborate on four constructsmovement, boundary, assemblage, and scaling - that span across the process orientations and that are essential to exploring how space is constituted and enacts organizing. Fourth, we discuss the insights and limitations of process studies on organizational space and suggest avenues for further research. Overall, this review aims to help researchers understand what space is and does in organizing as well as to ground their studies in theoretically coherent ways. This review is important and timely, especially because technology, globalization, and changing employment relations make space a more salient topic in management research.

\section{HISTORICAL BUILDING BLOCKS OF ORGANIZATIONAL SPACE}

The organization of space has been a concern of management scholars since the outset of the discipline. Beginning with Taylor (1911) who measured, calculated, and arranged factory floorplans for optimal efficiency, space was first conceptualized as a stable, physical environment that managers could manipulate and control to accomplish particular goals. To develop generalizable explanations, researchers took "snapshots" of certain spatial features, such as office buildings and layouts so that they and their effects could be replicated across contexts.

Since then, research interest on organizational space ebbed and flowed and paralleled the paradigmatic turns in management scholarship, particularly as represented in three theoretical views: objective, subjective, and critical (Elsbach \& Pratt, 2007; Hatch \& Cunliffe, 2013; Taylor \& Spicer, 2007). Studies on the instrumental design of space took an "objective view" to help managers promote workplace efficiency and productivity (e.g., Sundstrom \& Sundstrom, 1986). Research on organizational aesthetics and symbolism took a "subjective view" to examine the meanings, interpretations, and emotional climates linked to working spaces (e.g., Gagliardi, 1990). Finally, scholars with a "critical view" examined how physical structures materialized relations of dominance and submission in organizations (e.g., Dale \& Burrell, 2008).

In studying organizational space, researchers typically wrote from within their preferred paradigm and borrowed concepts, metaphors, and theories from other disciplines to explain their observations. Using borrowed concepts offered rich and novel ways to examine organizational space, but they typically led to compartmentalizing research into different camps or managerial arenas, as is evident in past 
reviews (Taylor \& Spicer, 2007). To understand best where the process studies of organizational space emerged, we integrated these silos by drawing on commonalities across the historical literature. These commonalities revealed four building blocks that surfaced from research across the literature, ones that would eventually foster the development of the process studies of space. Thus, these building blocks formed the conceptual foundation for researchers to move away from viewing space as a container to treating it as a process.

To develop this common zone, we examined six previous reviews of organizational space (Davis, 1984; Elsbach \& Pratt, 2007; Hatch \& Cunliffe, 2013; Hua, Loftness, Kraut, \& Powell, 2010; Taylor \& Spicer, 2007; Weinfurtner \& Seidl, 2019) and listed all central concepts about organizational space in tabular and graphic form. We then compared and contrasted concepts and their definitions to determine categories and relationships between them. We defined building blocks as foundational concepts that formed the core on which organizational space was conceived. Some concepts, such as visibility, openness, or privacy, characterized types of spaces but were not considered a defining feature of space. Through this process, we identified four concepts in the historical literature-physical structure, distance, workplace arrangements, and spatial scale-as the key building blocks of organizational space. In the next section, we discuss each building block and demonstrate how it surfaced in research that crossed different theoretical perspectives.

\section{Physical Structure}

The earliest research on organizational space centered on the physical structure or the designed environment of workspaces, including barriers such as doors and walls, partitions such as cubicles or bookshelves, and physical borders (Davis, 1984; Elsbach \& Pratt, 2007; Hatch \& Cunliffe, 2013). Initially, scholars studied physical structure to increase efficiency and productivity in organizations. Taking an objective perspective, they measured the length and height of physical structures, treated them as independent variables, and tested the likelihood of their effects on outcomes such as job satisfaction (Oldham \& Rotchford, 1983; Zalesny \& Farace, 1987) and performance (Sundstrom, Burt, \& Kamp, 1980). From a subjective perspective, researchers began to study how space users' interpretations of particular features of physical structures, such as the size and openness of a building, affected their subsequent behaviors
(Berg \& Kreiner, 1990; Larsen \& Schultz, 1990; Van Marrewijk, 2011). Critical researchers further showed how these structures facilitated managerial control by bringing workers together and creating separations between managers and employees (Halford, 2008; Kelly, 1980). Overall, researchers examined physical structures as preexistent and as comprising static boundaries that demarcated physical areas. In these historical studies, meanings, aesthetic qualities, and features of physical structure often changed, but space itself remained a static container shaped by fixed barriers and borders.

\section{Distance}

Closely related to physical structure, distance referred to the measurable space that formed a physical separation between two points (Hatch \& Cunliffe, 2013; Taylor \& Spicer, 2007). It differed from physical structure by centering on proximity "between a pair of individuals at a point in time...determin[ed] by the linear distance between the two persons" (Monge \& Kenneth, 1980: 110). From an objective view, distance emerged as a geographic concept that focused on the distribution of people, objects, and activities, such as the effects proximity had on various kinds of interaction (Allen, 1977; Pelz \& Andrews, 1966). Researchers who adopted a subjective approach argued that perceived proximity was as important as the measured physical space (Amin \& Cohendet, 2004; Wilson, O’Leary, Metiu, \& Jett, 2008). Their studies countered findings from the objective approach by showing that distance was a social and psychological concept, not just a characteristic of physical proximity (Wilson et al., 2008). From a critical view, distance became a way to coerce and control employees through centralized work processes that enacted and enabled surveillance practices (Baldry, 1999; Halford, 2008; Kornberger \& Clegg, 2004). Overall, this historical literature treated distance as a relatively stable concept that either fostered or constrained organizational actions and outcomes.

\section{Workplace Arrangements}

In addition to physical structure and distance, researchers examined workplace arrangements or the display, orientation, and alignment of material objects, artifacts, and stimuli in organizational space (e.g., furniture, machines, and equipment) (Davis, 1984; Elsbach \& Pratt, 2007). Scholars who embraced an objective view focused on the ways that cubicles 
and open-plan offices influenced organizational ambiance, fostered types of interactions, and shaped workflow (Hatch, 1987; Jewell \& Reitz, 1981; Sundstrom et al., 1980). From a subjective view, they revealed how workplace arrangements created symbolic meanings in addition to their practical use (Gagliardi, 1990; Olins, 1978; Strati, 1999; Van Marrewijk \& Yanow, 2010). Critical studies, in turn, showed how these arrangements regulated employee movements, behaviors, and identities (Dale \& Burrell, 2008; Hancock \& Spicer, 2011); aligned employees' expectations with certain practices in the labor market (Fleming \& Spicer, 2004); and shaped institutional norms and hierarchies (Halford \& Leonard, 2005). Thus, as a third building block, workplace arrangements became more fluid and mobile, but the organizational spaces in which these arrangements occurred in historical research remained stable and fixed.

\section{Spatial Scales}

Looking beyond a single organizational environment, scholars investigated spatial scale as the size and level of bundled spaces in which different organizational activities occurred, typically in a nested hierarchy of distinct but fixed geographic scopes (e.g., local, regional, national, and global) (O'Reilly, Allen, \& Reedy, 2018). Activities that occurred within an organization's built-environment constituted the microscale, ones that took place between organizational spaces functioned as the mesoscale, and activities that emerged in regions and states external to them created the macroscale (Burrell \& Dale, 2014; Taylor \& Spicer, 2007). From an objective perspective, researchers examined how the reach of an organization from the local to global scales and certain territories (e.g., regions) fostered particular outcomes (Chinitz, 1961; Muller \& Morgan, 1962; Swyngedouw, 1996). Scholars who adopted a subjective view demonstrated how actors experienced these scales, often in contrasting ways (Spicer, 2006). From a critical approach, studies focused on the power effects of domestic operations on global organizations in terms of social relations, regulations, and capital accumulation (Harvey, 1990; Massey, 2005; Zeller, 2000). Yet, the historical research on geographic scopes of organizations continued to treat space as more-or-less stable and hierarchically organized across scales.

\section{The Introduction of Space as a Process}

These four building blocks (Table 1) laid the foundation for traditional research on organizational space. More recently, and emerging from the objective, subjective, and critical approaches, researchers began to suggest that space was more fluid than had been previously conceived (Dale \& Burrell, 2008; Kornberger \& Clegg, 2004). They suggested that space was not a fixed container for organizational activities but was practiced and modified, often in different ways than was initially planned (Mengis, Nicolini, \& Gorli, 2018). These suggestions led to examining space as a process that was produced not only through planning but also how organizational members inhabited, occupied, and even imagined it.

In this shift, scholars drew on Henri Lefebvre (1991), a French sociologist who focused on space as socially produced through three processes: conceiving, or how people conceptualized, designed, planned, and represented it; perceiving, which encompassed how people interpreted and gave meaning to it; and living, or how individuals enacted it through activities in their everyday lives (Cairns, McInnes, \& Roberts, 2003; Kingma, Dale, \& Wasserman, 2018; Watkins, 2005). These three processes push and pull on each other in a dialectical relationship. Researchers drew on this framework to theorize space in complex, multifaceted ways (Giovannoni \& Quattrone, 2018; Liu \& Grey, 2017; Ratner, 2019; Taylor \& Spicer, 2007). For example, McNulty and Stewart (2015) used Lefebvre's framework to examine how board functioning was produced with governance space. They argued that iterative recurring behaviors directed corporations through the activities of secretaries and board members who planned and governed designs and the physical and temporal practices that enacted them.

Dale and Burrell (2008) further extended Lefebvre's framework through examining how space controlled organizational processes. They argued that organizational space emplaced people and things in particular locations, enchanted people with particular meanings and emotions, and constrained how people enacted workplace activities. To illustrate, Siebert et al. (2017) observed that the buildings of the Parliament House and the Advocates Library reproduced the status order of the Scottish legal system by assigning actors to particular rooms, evoking emotional responses through specified décor, and prescribing mobility patterns in the workplace.

In Lefebvre's (1991) original work, space emerged from activities situated in a particular moment in time as a holistic, negotiated phenomenon rather than a list of separate parts (Soja, 1998). Yet, the vast majority of organizational scholars who drew on this 


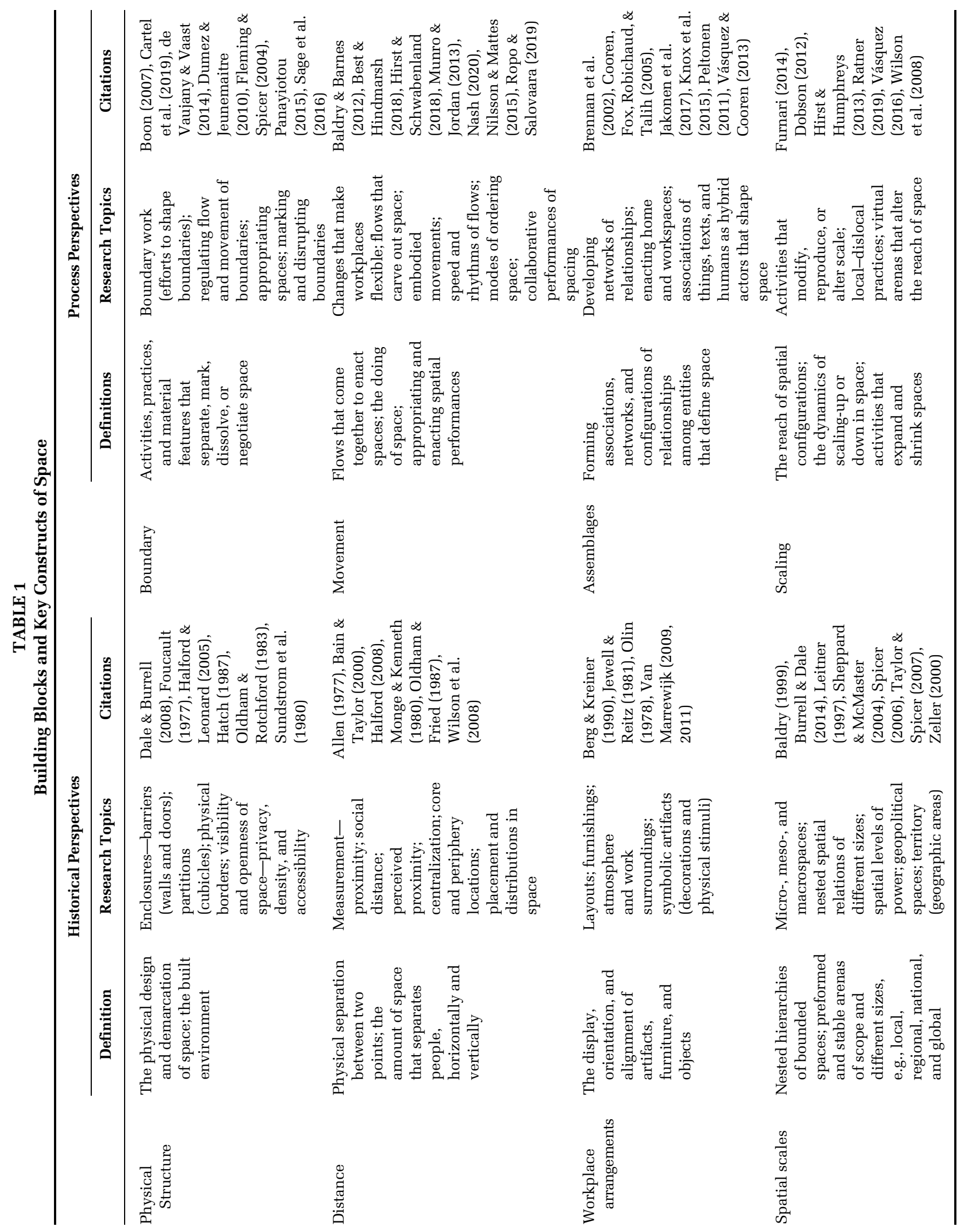


framework treated it as a heuristic of different research perspectives (Taylor \& Spicer, 2007) or embraced only one of the three processes. Other problems that resulted from piecemeal treatments of Lefebvre's framework included overemphasizing the human aspects of space, separating the social from the physical nature of it, and reifying the dynamic day-to-day actions that produced space (Beyes \& Steyaert, 2012; Vásquez, 2016). Despite these shortcomings, scholars who embraced Lefebvre's (1991) work ushered in a new generation of research in which space emerged, evolved, and transformed through social production and reproduction (Hernes, Bakken, \& Olsen, 2006).

To depict space as a process and distinguish it from traditional approaches, scholars used the gerund spacing rather than the noun space (Beyes \& Steyaert, 2012; Vásquez \& Cooren, 2013) and privileged emergence rather than the preexistent quality of space. Similar to Weick's (1974) use of the term organizing, the term spacing emphasized the events, practices, and ongoing activities that enacted the social and physical features of space, such as movements that shaped new boundaries, spatial performances, and physical arrangements. The rapid growth of scholarship on project-based tasks, teleworking, and collaborative entrepreneurship contributed to the rise of process studies on organizational space.

This shift in research calls for a comprehensive review of process studies that focuses on the generative activities of space in organizing (Langley, 1999; Tsoukas \& Chia, 2002). Process work in organizational studies is well-established, as evident by the number of books, conferences, special issues, and handbooks on this topic (Helin, Hernes, Hjorth, \& Holt, 2014; Hernes, 2014; Langley, Smallman, Tsoukas, \& Van de Ven, 2013; Langley \& Tsoukas, 2017). In general, the literature distinguishes between weak and strong process perspectives (Bakken \& Hernes, 2006). Research that embraces a weak process perspective centers on changes in a relatively stable substance that remains intact in its identity over time (Tsoukas \& Chia, 2002). Change, then, occurs in stages, cycles, or episodes that develop over time.

By contrast, scholars who adopt a strong process perspective contend that the world is constantly changing and evolving; change is not something that happens at a specific point in time, rather changing practices and activities bring organizational phenomena into existence (Langley \& Tsoukas, 2017). This work embraces a becoming ontology, highlights ongoing practices and performances, and treats organizing as a continual accomplishment. Although often cast as a dichotomy, weak and strong process perspectives exist on a continuum of varying degrees. We embrace this continuum in this review to examine how process-based studies of organizational space are positioned within it. In this way, we treat these different positions as process orientations. We begin this journey by describing how we conducted the literature review on process studies of organizational space.

\section{REVIEW METHOD}

\section{Sampling}

For this article, we followed two complementary procedures of sampling. First, we used the terms space, spacing, process, and organization to conduct an EBSCO database search for articles published on the topic of organizational space. This search produced a list of 308 articles from 51 different management and organizational journals. After creating this list, we read each abstract to ensure that organizational space was the central focus of the study and then we selected the articles that embraced a process perspective.

We defined a process perspective as any study that examined space "dynamically-in terms of movement, activity, events, change, and temporal evolution" (Langley, 2007: 271). Process could entail variations in objects, arrangements, and other material features, but the research itself had to cast organizational space as changing or being changed through movement, activity, ongoing events, or developments over time. In sampling the literature, we focused on process studies that captured the physicality of space and excluded ones that treated space metaphorically, for example, research on psychological spaces (Weinfurtner \& Seidl, 2019). If we were unsure whether space was the central phenomenon or whether the study embraced a process perspective, two or more coauthors examined the article and reached a consensus as to whether to include or exclude it. We also used a reference list checking technique (Greenhalgh \& Peacock, 2005) in which we scanned the references of each article for additional process studies of space that were not included in our sample. These two steps narrowed our original set of 308 articles to 163 articles that met our criteria in conducting this review (Table 2).

\section{Analysis}

To determine the type of process study, we read each article and identified how the authors defined 
TABLE 2

Key References for Review

\begin{tabular}{|c|c|}
\hline Spacing Process & References \\
\hline Developing $(n=11)$ & $\begin{array}{l}\text { Baldry \& Barnes (2012), Brennan et al. (2002), Carmona, Ezzamel, \& Gutiérrez (1997), Coradi et al. (2015), Dobson } \\
\text { (2012), Maaninen-Olsson \& Müllern (2009), McElroy \& Morrow (2010), Nilsson \& Mattes (2015), Sailer (2011), } \\
\text { Skogland \& Hansen (2017), Zalesny \& Farace (1987) }\end{array}$ \\
\hline Transitioning $(n=35)$ & $\begin{array}{l}\text { Bucher \& Langley (2016), Cartel et al. (2019), Clegg, Cunha, \& Rego (2012), Costas (2013), Courpasson et al. (2017), } \\
\text { Derksen, Blomme, de Caluwé, Rupert, \& Simons (2019), Elmholdt et al. (2018), Furnari (2014), Hardy \& } \\
\text { Maguire (2010), Hjorth (2005), Howard-Grenville, Golden-Biddle, Irwin, \& Mao (2011), Iedema \& Carroll } \\
\text { (2011), Iedema \& Rhodes (2010), Jansen (2008), Jones (2018), Kellogg (2009), Kociatkiewicz \& Kostera (2011, } \\
\text { 2015), Lee et al. (2020), Lewis (2008), Mair \& Hehenberger (2014), Michaud (2014), Ometto, Gegenuber, Winter } \\
\text { \& Greenwood (2019), Perkmann et al. (2019), Pöyhönen (2018), Rao \& Dutta (2012), Reinecke (2018), Shortt } \\
\text { (2015), Sturdy et al. (2006), Vaccaro \& Palazzo (2015), Vesala \& Tuomivaara (2018), Wilhoit (2017), Wilner, } \\
\text { Christopoulous, \& Alves (2017), Zhang, Spicer, \& Hancock (2008), Zietsma \& Lawrence (2010) }\end{array}$ \\
\hline Imbricating $(n=36)$ & $\begin{array}{l}\text { Alonso González (2016), Bar-Lev \& Vitner (2011), Berti, Simpson, \& Clegg (2018), Boon (2007), Brown \& O’Hara } \\
\text { (2003), Dale (2005), Decker (2014), de Vaujany \& Vaast (2014), Dumez \& Jeunemaitre (2010), Ernst (2017), } \\
\text { Fayard \& Weeks (2007), Fleming \& Spicer (2004), Gander (2015), Gieryn (2000), Hirst (2011), Hirst \& } \\
\text { Schwabenland (2018), Hislop \& Axtell (2009), Hydle (2015), Jarzabkowski et al. (2015), Kingma (2019), } \\
\text { Kornberger \& Clegg (2004), Liu \& Grey (2017), Munro (2018), Munro \& Jordan (2013), Peltonen (2011), Petani \& } \\
\text { Mengis (2016), Raulet-Croset \& Borzeix (2014), Siebert et al. (2017), Spicer (2006), Tietze (2005), Tyler \& Cohen } \\
\text { (2010), Waistell (2006), Wapshott \& Mallett (2011), Wasserman \& Frenkel (2011, 2015), Zhang \& Spicer (2014) }\end{array}$ \\
\hline Becoming $(n=39)$ & $\begin{array}{l}\text { Allen \& Brown (2016), Bazin \& Naccache (2016), Beyes (2010), Beyes \& Michels (2011), Beyes \& Steyaert (2012), } \\
\text { Biehl (2019), Biehl-Missal (2016), Borch (2009), Cairns (2002), Cairns et al. (2003), Dashtipour \& Rumens } \\
\text { (2018), Daskalaki \& Kokkinidis (2017), Daskalaki, Stara, \& Imas (2008), Fabbri (2016), Giovannoni \& Quattrone } \\
\text { (2018), Jakonen et al. (2017), Jones (2014), Katila et al. (2019), Knox, O’Doherty, Vurdubakis, \& Westrup (2007), } \\
\text { Knox et al. (2015), Küpers (2015), Lucas (2014), Maréchal et al. (2013), Mengis et al. (2018), Michels \& Steyaert } \\
\text { (2017), Molli, Mengis, \& van Marrewijk (2019), Panayiotou (2015), Paquette \& Lacassagne (2013), Ratner } \\
\text { (2019), Riach \& Wilson (2014), Ropo \& Höykinpuro (2017), Ropo \& Salovaara (2019), Ropo et al. (2013), Sewell } \\
\text { \& Taskin (2015), Skoglund \& Holt (2020), Steyaert (2010), Thanem (2010, 2012), Verduyn (2015) }\end{array}$ \\
\hline Constituting $(n=42)$ & $\begin{array}{l}\text { Best \& Hindmarsh (2018), Callahan (2013), Cnossen \& Bencherki (2019), Cohen (2010), Cooren \& Fairhurst } \\
\text { (2004), Crevani (2018a, 2018b), Czarniawska (2004), D’Mello \& Sahay (2007), Fahy, Easterby-Smith, \& Lervik } \\
\text { (2014), Hansen (2004), Herod, Rainnie, \& McGrath-Champ (2007), Hirst \& Humphreys (2013), Hoskin (2004), } \\
\text { Husted \& Plesner (2017), Jones, McLean, \& Quattrone (2004), Kingma (2016), Komporozos-Athanasiou, } \\
\text { Thompson, \& Fotkai (2018), Kornberger \& Clegg (2003), Knox et al. (2008), Lancione \& Clegg (2013), McNulty \& } \\
\text { Stewart (2015), Nash (2018, 2020), Oittinen (2018), Papazu \& Nelund (2018), Peltonen (2012), Richardson } \\
\text { \& McKenna (2014), Rodgers et al. (2016), Sage et al. (2016), Simpson, Tracey, \& Weston (2018), Sivunen \& } \\
\text { Putnam (2019), Våland \& Georg (2018), Van Marrewijk \& Van den Ende (2018), Vásquez (2016), Vásquez, } \\
\text { Brummans, \& Groleau (2012), Vásquez \& Cooren (2013), Vermeulen (2011), Vidaillet \& Bousalham (2020), } \\
\text { Wilhoit (2018), Wilhoit \& Kisselburgh (2015), Yeung (1998) }\end{array}$ \\
\hline
\end{tabular}

space, incorporated concepts, posed research questions, drew on particular theorists, selected research settings, used particular paradigms, reported findings, and drew conclusions. Next, we clustered the kinds of spatial processes that the authors identified based on their treatment and assumptions about process. First, we classified them into the categories of weak versus strong process research, as described earlier (Bakken \& Hernes, 2006; Langley \& Tsoukas, 2017). To do this, we relied on words that the authors used in depicting their research, for example, for weak process perspectives, words such as stage, phase, periodic, evolutionary, over time, cycles, clock time, and chronological development surfaced in the research, whereas for strong process perspectives, authors used such terms such as ongoing, unfolding, continual, becoming, duration, generative, performative, eventdriven, potential, and experiential time.

\section{Categorizing Articles}

After sorting the articles into weak and strong process perspectives, we compared how the researchers conceived of organizational space itself. On the one extreme, researchers treated space as an enduring, pre-given object that existed independently from organizational activities, and on the other end, they conceived of space as evolving and emerging based on the relationships between actors and objects. To make this determination, we relied on the analytical foci and definitions of space for each article. Researchers who treated space as a 
substance or a container that changed over time conceived of it as analytically fixed (Callon \& Law, 2004), whereas scholars who viewed space as emerging from the relationships among multiple actors and things centered on activities and practices that constituted space at a given moment in time. This procedure uncovered five related but distinct process orientations to organizational space, the labels of which we derived from the articles themselves.

Two orientations-developing and transitioningtreated space as a concrete, pre-given substance. The developing orientation paralleled historical studies because researchers conceived of space as a substance and took a weak process perspective to explain how episodic spatial changes led to various organizational outcomes. Of the 163 articles included in this review, we classified only 11 of them in the developing orientation. The transitioning orientation also treated space as an intact substance, but changes occurred through transitioning between spaces, such as lobbies and hallways as activity-based and episodic forms of organizing. In this review, 35 articles fell into the transitioning orientation.

Three additional process orientations emerged from different underlying assumptions in which researchers treated space as emerging through continuously changing relationships between humans and material elements; thus, these studies revealed a strong process perspective. Imbricating focused on ongoing activities that brought different spatial elements together to develop particular affordances or appropriations. This orientation consisted of 39 articles. The orientations of becoming and constituting (39 for becoming and 42 for constituting) treated space as continuously produced from ongoing, openended performances. Whereas becoming studies concentrated on situated performances that invested space with different meanings, constituting studies focused on how certain spaces gained their form and stability over time. During our analysis, we observed that the strong process orientations, particularly becoming and constituting, emerged more recently than did the weak process ones. However, the five orientations did not reflect a chronological progression because each of them included recently published articles. In the next section, we elaborate on and illustrate these five distinct orientations.

\section{A TYPOLOGY OF PROCESS ORIENTATIONS}

The five orientations to the study of organizational space-developing, transitioning, imbricating, becoming, and constituting-reveal important differences in assumptions, theoretical foundations, methods, and types of findings. Moreover, as Table 3 notes, differences in key constructs subsumed under each orientation offer opportunities for advancing theory on organizational space, particularly in moving away from reifying spaces as containers (Beyes \& Steyaert, 2012).

\section{Five Orientations to Process Studies of Organizational Space}

Orientation I: Developing. The developing orientation paralleled traditional views of organizational space by focusing on the physical environment and treating it as changing in episodic ways. The studies in this orientation cast space as a relatively stable phenomenon that managers, designers, and architects could change over time, often in controlled ways. Researchers presumed that space could be quantified, generalized, and represented. In particular, studies of spatial renovations, repurposing, and rearrangements examined interventions in workspace changes. Inspired by environmental psychologists (Oldham \& Brass, 1979; Sundstrom et al., 1980), scholars who embraced this orientation viewed space as a separate phenomenon that influenced patterns of organizing.

Specifically, researchers examined how changes in workspaces influenced individual behaviors, perceptions, ways of relating and interacting, and organizational outcomes. They focused on how the removal of barriers, the manipulation of distance, and alterations in office layouts changed visibility, accessibility, privacy, and proximity. For instance, Coradi, Heinzen, and Boutellier (2015) showed how the removal of partitions stimulated cross-functional communication and enhanced organizational learning and innovation. Nilsson and Mattes (2015) illustrated how bringing geographically dispersed teams together in face-to-face meetings before beginning a project promoted trust among members. McElroy and Morrow (2010) investigated how office designs that moved from a 1970s cubicle arrangement to an open office plan led to positive perceptions of the organization's culture and increased commitment to the firm.

In effect, studies that fell into the developing orientation examined the variance between past and new spatial designs. With the aim of generalizability, most investigations concentrated on outcomes rather than on the enactment of these designs.

Orientation II: Transitioning. Transitioning as the second process orientation centered on the dynamics of inhabiting new spaces, typically ones in which the organizational norms were temporarily 
TABLE 3

A Typology of Process Studies of Organizational Space

\begin{tabular}{|c|c|c|c|c|c|}
\hline $\begin{array}{l}\text { Spacing } \\
\text { Process }\end{array}$ & Developing & Transitioning & Imbricating & Becoming & Constituting \\
\hline Assumptions & $\begin{array}{l}\text { Space is preformed; } \\
\text { physical } \\
\text { environments afford } \\
\text { organizational } \\
\text { outcomes; spaces } \\
\text { change episodically }\end{array}$ & $\begin{array}{l}\text { Preexistent spaces } \\
\text { that are transitory } \\
\text { (always in flux); } \\
\text { spaces on borders, } \\
\text { outside, or in- } \\
\text { between }\end{array}$ & $\begin{array}{l}\text { Space as enacted } \\
\text { through social } \\
\text { practices with } \\
\text { other entities; } \\
\text { entanglements that } \\
\text { change over time }\end{array}$ & $\begin{array}{l}\text { Space as } \\
\text { performative; } \\
\text { embodied } \\
\text { practices that are } \\
\text { fleeting and } \\
\text { constantly } \\
\text { unfolding }\end{array}$ & $\begin{array}{l}\text { Space as ongoing } \\
\text { choreographed } \\
\text { actions and } \\
\text { interactions of } \\
\text { human and } \\
\text { material elements }\end{array}$ \\
\hline Theorists & $\begin{array}{l}\text { Oldham \& Brass } \\
\text { (1979), Sundstrom } \\
\text { \& Sundstrom } \\
\text { (1986) }\end{array}$ & $\begin{array}{l}\text { Augé (1995), Evans \& } \\
\text { Boyte (1986), } \\
\text { Turner (1974) }\end{array}$ & $\begin{array}{l}\text { de Certeau (1984), } \\
\text { Gibson (1986), } \\
\text { Giddens (1984), } \\
\text { Graumann (1976) }\end{array}$ & $\begin{array}{l}\text { Deleuze \& Guattari } \\
\text { (1987), Foucault } \\
\text { (1986), Latour } \\
\text { (1993), Massey } \\
\text { (2005), Thrift (2008) }\end{array}$ & $\begin{array}{l}\text { Deleuze \& Guattari } \\
\text { (1987), Foucault } \\
\text { (1986), Latour } \\
\text { (1993), Massey } \\
\text { (2005) }\end{array}$ \\
\hline $\begin{array}{l}\text { Related } \\
\text { concepts }\end{array}$ & $\begin{array}{l}\text { Boundary, proximity, } \\
\text { distance, territory, } \\
\text { and workplace } \\
\text { design }\end{array}$ & $\begin{array}{l}\text { Liminal spaces, non- } \\
\text { spaces, interspaces, } \\
\text { free spaces, and } \\
\text { border zones }\end{array}$ & $\begin{array}{l}\text { Appropriations, } \\
\text { affordances, } \\
\text { creating tactics, } \\
\text { and strategies }\end{array}$ & $\begin{array}{l}\text { Atmospheres, affects, } \\
\text { multiplicity, } \\
\text { speed, and } \\
\text { duration }\end{array}$ & $\begin{array}{l}\text { Modes of ordering, } \\
\text { spatial movements, } \\
\text { spatial patterns, } \\
\text { rhythms, and flows }\end{array}$ \\
\hline $\begin{array}{l}\text { Exemplary } \\
\text { publications }\end{array}$ & $\begin{array}{l}\text { Brennan et al. (2002), } \\
\text { Coradi et al. (2015), } \\
\text { McElroy \& Morrow } \\
\text { (2010) }\end{array}$ & $\begin{array}{l}\text { Courpasson et al. } \\
\text { (2017), Furnari } \\
\text { (2014), Howard- } \\
\text { Grenville et al. } \\
\text { (2011), Shortt } \\
\text { (2015), Sturdy et al. } \\
\text { (2006) }\end{array}$ & $\begin{array}{l}\text { de Vaujany \& Vaast } \\
\text { (2014), Fayard \& } \\
\text { Weeks (2007), } \\
\text { Hislop \& Axtell } \\
\text { (2009), Munro \& } \\
\text { Jordan (2013) }\end{array}$ & $\begin{array}{l}\text { Beyes (2010), Beyes } \\
\text { \& Michels (2011), } \\
\text { Biehl-Missal } \\
\text { (2016), Knox et al. } \\
\text { (2015) }\end{array}$ & $\begin{array}{l}\text { Knox et al. (2008), } \\
\text { Sage et al. (2016), } \\
\text { Vásquez (2016), } \\
\text { Wilhoit \& } \\
\text { Kisselburgh (2015) }\end{array}$ \\
\hline
\end{tabular}

suspended. This orientation departed from the developing one by shifting away from episodic change to treat movement as purposeful and transitory. Inspired by anthropologists, such as Turner (1974) and Augé (1995) and sociologists Evans and Boyte (1986), transitional spaces, such as corridors, toilets and stairways, exist in every organization. In this orientation, researchers embraced a weak process perspective to examine fluid boundaries in-between, isolated within, or lying outside of formal spaces. Thus, scholars viewed the process of transitioning between formal and informal spaces as unique and uncertain, that is, "each dinner," "meeting," or "commute" differed from other similar spatial events (Wilhoit, 2017). Similar to the developing orientation, scholars whose work fell into this category also 
conceived of space as a substance that could be observed, marked, and measured.

Studies that embraced this orientation focused on transitioning between permanent and temporary spaces, namely, liminal, free, interstitial, and nonplaces. In liminal spaces, actors suspended organizational norms, behaviors, and social positions to relax or even resist managerial control (Turner, 1974). Similarly, free spaces as small-scale settings outside of managerial control offered opportunities to mobilize individuals for collective action (Polletta, 1999), whereas interstitial spaces were "small-scale settings [in which] individuals from different fields interact[ed] occasionally and informally" to explore creative ideas (Furnari, 2014: 440). Scholars cast nonplaces as transient and interchangeable spaces, such as airports and coffee shops that offered familiarity and anonymity (Augé, 1995). Thus, transitioning centered on moving within and between organizational spaces where employees could relax, resist, and engage in collective action to generate new ideas.

In this orientation, researchers focused on the conditions of these in-between spaces. First, organization members located physical spaces on the fringe of organizations and kept certain individuals away from them (Boon, 2007; Kellogg, 2009). For instance, Courpasson et al. (2017) observed that physical areas, such as dark, messy basements of a factory outside the view of managers, gave resistors energy, enthusiasm, and security in reacting to managerial actions. Similarly, Shortt (2015) examined how hairdressers used physical features such as corridors, stairwells, and toilets as transitory spaces to obtain a sense of privacy and inspiration away from their clients. Moreover, activities such as business meals away from organizational settings allowed consultants to explore political dynamics and assess the trustworthiness of clients and colleagues (Sturdy et al., 2006).

Second, because transitioning spaces allowed norms to be suspended (Lee, Mazmanian, \& Perlow, 2020), they offered opportunities for people to connect with others that they normally did not encounter. These connections might be made based on shared interest (Furnari, 2014), emotions (Elmholdt, Clausen, \& Madsen, 2018), or politics (Reinecke, 2018). Third, through suspended norms and new connections, transitioning spaces compelled "new arrangements" (Daskalaki et al., 2017) and "hybrid combinations" (Perkmann, Mckelvey, \& Phillips, 2019) which could foster creativity (Shortt, 2015), reflection (Iedema \& Carroll, 2011), innovation (Cartel, Boxenbaum, \& Aggeri, 2019), and resistance (Reinecke,
2018). These arrangements surfaced as new kinds of organizational spaces such as university-industry centers (Perkman et al., 2019), incubators (Ometto et al., 2019) fab-labs (Furnari, 2014), and social networks (Wilner et al., 2017), which also rearranged ways of organizing. Fourth, because transitioning spaces were protective places for new arrangements, they could scale up from an individual to an organization and to a region. Ometto et al. (2019) demonstrated how two types of transitional spaces were essential to maintaining the social enterprise mission of a Brazilian organization.

Thus, transitioning focused on moving from formal to informal spaces that were in-between, outside, or on the border of organizations. As relatively stable structures, employees moved to different locations to challenge patterns of organizing. Importantly, both the developing and transitioning orientations embraced weak process perspectives and substantive views of space.

Orientation III: Imbricating. The third orientation, imbricating, cast organizational space as material and relational practices that became interwoven into bundles (Leonardi, 2011). Inspired by practice theories (Bourdieu, 1977; de Certeau, 1984; Giddens, 1984) and sociomaterial thinking (Leonardi \& Barley, 2010; Orlikowski, 2007), imbricating occurred in the everyday activities of organizing that became interwoven and changed over time.

Scholars whose work fell into this strong process orientation treated space as comprising interconnections among the people, things, and activities that surfaced in organizing. Space emerged from the social and material objects that came together and continuously changed in organizational practices. Consequently, researchers in this orientation framed organizational space as performative, open to change, and iteratively evolving through interconnections with different human-material arrangements. With this view, space did not have inherent qualities, but acquired its form and features in, by, and through the practices that comprised it.

Within the management literature, studies examined the affordances (Gibson, 1986) and appropriations (Graumann, 1976) that emerged in spatial practices. Affordances referred to what a given physical or spatial setting permitted when actors perceived it (Fayard \& Weeks, 2007). Research on spatial affordances cast space as social, but also material, and as enacted in organizational practices that changed over time. Studies revealed that the "anytime, anywhere" mantra of mobile work ignored the contextual affordances of particular work practices 
(Brown \& O'Hara, 2003; Hislop \& Axtell, 2009; Tietze, 2005; Wapshott \& Mallett, 2011). That is, an airport lounge or a car only allowed workers to accomplish certain tasks, such as talking on a phone, and was ineffective for other functions, such as doing concentrated work (Brown \& O’Hara, 2003; Hislop \& Axtell, 2009). Similarly, working from home afforded temporary workspaces by requiring employees to rearrange their domestic spaces, clear off tables, communicate with family members while at work, and maintain their organizational external ties (Tietze, 2005).

Affordances also created types of spaces through changing social and material interfaces. Specifically, Jarzabkowski et al. (2015) illustrated how different body-material-discursive connections afforded particular types of strategy work. For instance, the practice of orienting several employees to a computer screen so everyone could see it at once created mutual space that afforded collaboration, whereas focusing on a single employee at the screen afforded private space for calculation work. In this way, the orientation of people and artifacts enacted spaces that afforded particular types of work activities (Kornberger \& Clegg, 2004).

Appropriation referred to transforming space into something useful (Graumann, 1976) through physically modifying it to serve "the needs and possibilities of a particular group" (Dale, 2005: 658). Research on appropriations examined how users altered physical environments to garner legitimacy, claim territory, or contest power relations. For instance, Decker (2014) showed how, to "achieve greater legitimacy" (p. 57), corporations in Ghana and Nigeria leveraged buildings to help create a particular social memory that aligned with external stakeholders' expectations. Similarly, de Vaujany and Vaast (2014) demonstrated how stakeholders at a French university drew on spatial legacies to appropriate or affirm the university's traits, to divert audiences from reappropriating the building, and to dis-appropriate or strip the space of its previous institutional use.

To lay claim to a territory, employees also appropriated space (de Certeau, 1984). For example, Munro and Jordan (2013) described how street performers at the Edinburgh Fringe Festival formed a boundary and raised the height of a temporary stage to appropriate private space as a public area, whereas Zhang and Spicer (2014) demonstrated how employees at a Chinese tax authority appropriated nonorganizational spaces with ritualized practices that maintained bureaucratic hierarchy. Moreover, Dumez and Jeunemaitre (2010) described how multinational corporations, countries, and regions negotiated, decided, and solidified airspace boundaries after the deregulation of commercial aviation.

In other studies, appropriations of space contested dominant norms. To illustrate, Dale (2005) showed how an open-plan office created divisions between teams through appropriating furniture that blocked networking and communication flow. Employees used bookshelves to prevent surveillance and they set up a calm professional ambiance to create an informal buzz. Similarly, Wasserman and Frenkel (2015) described how employees at the Israeli Ministry of Foreign Affairs modified their workspace designs to construct, reproduce, and challenge gender and class distinctions. Yet, instead of making radical organizational changes, organizational members enacted these bounded appropriations in accordance with gender-based societal norms (Tyler \& Cohen, 2010).

Unlike the developing and transitioning studies, researchers whose work fell into the imbricating orientation moved away from treating space as a substance. In effect, scholars in diverse areas of organizational studies, such as technology, strategy, and institutional change, conceived of space as imbricated through interlocking relationships among human and material features. Even though some scholars lapsed into prescriptive sets of relationships or generalizable conclusions (Fayard \& Weeks, 2007), researchers undertook the journey to study spacing rather than treating space as a preexisting thing. Yet, focusing on affordances and appropriations did not center directly on how spaces continually changed.

Orientation IV: Becoming. Scholars who embraced the becoming orientation, however, made this shift to the "continuous production of the new" (Massey, 2005: 23). Inspired by human geography (Thrift, 2008), actor-network theory (Latour, 2005), and the philosophy of Deleuze and Guattari (1987), research in this orientation focused on the emergence of spatial practices that cast space as continually formed and reformed through changing interactions between humans and material artifacts linked to a situation (Knox, O’Doherty, Vurdubakis, \& Westrup, 2015). Research with this orientation framed space as an emergent, ongoing process rather than as an entity. Scholars studied how shifting interactions, people, and objects made organizational spaces continuously anew, often in multiple ways at once. For instance, at one moment, a coworking space functioned as a boardroom while simultaneously becoming a creativity workshop with different 
people, tools, artifacts, and activities (Fabbri, 2016). Thus, in this orientation, space consisted of multiple, fleeting interactions of human and material features (Thrift, 1999).

To account for the ephemeral qualities of space, researchers who embraced this orientation introduced several new scholarly approaches, including writing and producing knowledge with narrative styles that incorporated reflexivity (Vásquez, 2016), offering multiple interpretations (Beyes \& Michels, 2011), and using concepts that captured embodied spatial experiences (Beyes \& Steyaert, 2012). In particular, these scholars moved away from preexistent notions of space and focused on one or more of the following: material features and ongoing everyday practices, multiple possibilities and alternative politics, embodiment and the body, affect and sensation, and speed and rhythms of movements that created space (Beyes \& Steyaert, 2012). Research that centered on materiality and everyday practices examined the fleeting and constantly unfolding ways that objects, bodies, and physical elements became entangled to create space. For example, studies demonstrated how everyday activities could disrupt encounters (Daskalaki \& Kokkinidis, 2017; Fabbri, 2016; Jakonen, Kivinen, Salovaara, \& Hirkman, 2017; Sergot \& Saives, 2016) or could create surprising happenings (Beyes, 2010; Knox et al., 2015), which reordered space and influenced organizing. These encounters were unpredictable and "gave birth to something new" that was often valuable (Jakonen et al., 2017: 238).

To decipher how changes in spatial relations disrupted organizing, researchers examined events that were on the cusp of becoming new spatial and organizational forms. Specifically, Michels and Steyaert (2017) referenced how a marketing team's design of a new showroom space for luxury cars was unsuccessful because the productive force of art and design shifted over time. Also, Knox et al. (2015) demonstrated how an Asian-looking man who threw a bag and cellphone onto the apron of a British airport became "a spatial happening." The airport norms since $9 / 11$, the integration of activities with material objects (potential bomb and detonator), and the restrictions placed on airport space suggested a potential terrorist attack. Over time, however, the spaces began to resemble an airport again, and these practices and objects reverted to being "just" a bag and a mobile phone and no longer a potential triggering device (Knox et al., 2015: 1011).

In addition to everyday practices, scholars who embraced this orientation examined the possibilities of alternative spaces. Specifically, they showed how ongoing activities created "other spaces" (Foucault, 1986) or counter-spaces that temporarily interrupted organizational life by offering possibilities for play, creativity, and new organizational roles (Beyes \& Michels, 2011; Dashtipour \& Rumens, 2018). "Other spaces” emerged through localizing events, creating cracks in dominant spaces, avoiding categorization, and developing alternative ways of doing. Vidaillet and Bousalham (2020) demonstrated how coworking spaces allowed for heterogeneous and sometimes contradictory economic practices to coexist, and Jones (2014) described how a university garden, which fostered a "bio-cultural connection," enacted spatial restoration in which faculty members countered institutional pressures.

A third feature that characterized scholarship in this orientation was focusing on connections between bodies, actions, and movements, known as embodied practices that created certain kinds of organizational spaces (Beyes \& Steyaert, 2012). Typically, researchers studied how embodied activities aligned with key organizational processes of learning, leading, and knowing. Specifically, Ropo et al. (2013) argued that leadership emerged through spatial activities linked to embodied practices and through emotional, kinesthetic knowledge. Similarly, Biehl (2019) demonstrated how leaders and followers reciprocated embodied movements that kept them in continuous situational adaption.

Closely related, the fourth feature, affect, and sensation, referred to the "mutual capacities of humans to affect and be affected by one another" (Michels \& Steyaert, 2017: 82). For instance, Verduyn (2015) described how the culmination of long hours and strong smells moved entrepreneurs to develop alternative spaces to avoid being "sick to their stomachs." Dashtipour and Rumens (2018) demonstrated how the entrepreneurial efforts of a Swedish anti-racist magazine generated spaces of anxiety that disrupted established orders and led to the magazine's demise. Michels and Steyaert (2017) described how affective atmospheres, or the feel of spaces, emerged from a music ensemble's engagement with unpredictable weather, moods of the musicians, and the urban life of performance sites.

Speed and rhythm comprised the fifth feature in the becoming orientation to organizational space. Speed referred to the duration of movements, whereas rhythm encompassed temporalities, flow, cadence, and patterns. To illustrate, in a study of a Nordic startup accelerator, Katila, Kuismin, and Valtonen (2019) showed how particular fast-paced work emanated from an 
accelerator and how the participants learned these rhythms through embodied spatial practices. This study also highlighted how participants fostered these fast-paced rhythms by manipulating the social and material elements of space, including background music, workshop activities, and digital timers. Similarly, Verduyn (2015) described how heterogeneous rhythms of a startup company (i.e., body, mechanical, and natural) unfolded in waves that enacted the affective and bodily reactions of entrepreneurship.

As these studies showed, researchers in the becoming orientation conceived of space as performative, emergent, embodied, and fleeting. Scholars focused on the multiple features of space, activities, and objects that became interwoven in performances. Yet, unlike imbricating, investigations privileged the ongoing activities that produced space, including sensations, rhythms, encounters, events, movements, and flows that became intertwined with affect, bodies, and atmospheres (Beyes \& Steyaert, 2012). Even though this approach comprised more than a fifth of the articles reviewed, it tended to focus on niche organizations. However, recent leadership and entrepreneurship studies (Ropo \& Salovaara, 2019; Ropo et al., 2013; Verduyn, 2015) departed from this trend to demonstrate how the becoming orientation contributed to traditional managerial domains.

Orientation V: Constituting. Whereas the becoming orientation focused on space as being in perpetual motion linked to the constant flow of human and material relations, the constituting orientation shifted attention to the continual structuring, restructuring, arranging, shaping, and composing of space that gave organization its spatial form and stability. In the constituting orientation, space endured through activities, events, and practices that constantly ordered and re-ordered it, for example, by placing certain objects in particular locations, separating them from each other, or aligning spatial activities with routine practices (Richardson \& McKenna, 2014). Inspired by postmodern geographers (Massey, 2005; Thrift, 2008), actor-network theorists (Latour, 2005), and communication as constituting organization (CCO) approaches (Cooren, 2006), scholars who worked in this orientation unpacked how this constant ordering and re-ordering of space brought organizations into being and made them durable.

The constituting orientation to organizational space crossed a range of managerial topics, including leadership (Crevani, 2018b), professional work (D’Mello \& Sahay, 2007), project management (Fahy, EasterbySmith, \& Lervik, 2014; Sage, Justesen, Dainty, Tryggestad, \& Mouritsen, 2016), governance (McNulty \& Stewart,
2015), dispersed teams (Oittinen, 2018; Sewell \& Taskin, 2015), and organizational change (Cnossen \& Bencherki, 2019; Vásquez, 2016; Wilhoit \& Kisselburgh, 2015). The growth in studies that embraced this orientation (Wilhoit, 2018) made it ideal for investigating complex organizational concerns.

Research in this orientation centered on modes of ordering objects, subjects, and artifacts (Law, 1994) into logics or patterns that formed hybrid spaces of dissimilar features (Knox, O’Doherty, Vurdubakis, \& Westrup, 2008; Richardson \& McKenna, 2014). To illustrate, Knox et al. (2008) showed how an international airport constituted space through conflicting modes of ordering. During times when passengers' check-in queues were long, staff forced bags onto the luggage belt, which came into conflict with the spatial processing of passengers. These conflicting modes of ordering formed new spaces that produced blockages and slowed down the check-in process.

Movements (de Certeau, 1984) also contributed to constituting space through flows that aggregated and aligned activities. For example, Wilhoit and Kisselburgh (2015) demonstrated how the spatial movements of bicycle commuters constituted a collective group, even if the cyclists did not see themselves as unified. However, drivers and city planners drew on the aggregation of spatial movements to align them as a cycling collective.

These aggregated movements also formed recipes that facilitated the constituting of organizational space (Amin, Massey, \& Thrift, 2003). Recipes referred to the guidelines for getting things done, interpreting what had been done, and helping actors make sense of actions. In a study of a Chilean outreach organization, Vásquez (2016) showed how a network, a region, and a trajectory constituted different types of spaces. Specifically, recipes directed members either to get more people involved (network), to mark off boundaries for outreach (region), or to develop stories of inclusion/ exclusion (trajectory). These recipes constituted spaces that fostered different kinds of distributed organizing.

Another line of research in this orientation examined the interfaces among space, time, and rhythms of social actions (Orlikowski \& Yates, 2002). Fahy et al. (2014) uncovered how the intermingling of space and time both fostered and constrained knowledge sharing and organizational learning. They observed that the spatial-temporal rhythms of service engineers clashed with those of project engineers to inhibit knowledge sharing. In one instance, a service engineer entered a customer site in the middle of the 
night to solve a problem that required project expertise, but because project engineers who had this knowledge worked only nine to five, service personnel were unable to resolve the situation. Thus, the rhythms of space and time between the different professions clashed in ways that prevented organizational learning. In another study, Sage et al. (2016) found that the location and timing of the breeding cycles of a protected species of frogs delayed the completion of a construction project.

As these studies showed, research that used the constitutive orientation examined the events, activities, and practices that ordered the relationships between humans and material elements of space and made these spatial configurations durable. Scholars focused on modes of ordering, aggregated spatial movements, recipes that evoked spatial images, space-time rhythms, and spatiotemporal configurations that changed over time to constitute organizational space. Thus, space not only emerged from the ongoing flow of actions and interactions but also appeared in more or less durable arrangements that characterized the very nature of an organization. In this orientation, then, enacting space constituted organizing/organization through the arrangements that formed collectives, shaped the order of them, and determined how others recognized them as organizations.

Taken together, these five orientations-developing, transitioning, imbricating, becoming, and constitutingrevealed how scholars embraced both weak and strong process perspectives in studying organizational space. Scholars who used weak perspectives viewed space as a preexisting container characterized by episodic changes or transitions between spatial arenas. By contrast, researchers who adopted strong perspectives focused on the emergence of space or the continuous, ongoing construction of it through interconnections among material objects and organizational activities. Even though the strong process perspectives were similar in many ways, they differed in foci and in how spatial practices contributed to organizing. With imbricating, spatial practices centered on affordances and appropriations; in becoming, scholars examined emerging and fleeting spatial performances; and in constituting, researchers focused on the spatial patterns and configurations that brought organizations into existence. Importantly, in all three orientations that relied on a strong process perspective, space emerged as interwoven bundles or configurations of multiple human and material features. Compared to the historical approaches, these studies call for developing new key constructs of organizational space in light of these process orientations.

\section{KEY CONSTRUCTS: PROCESS STUDIES OF ORGANIZATIONAL SPACE}

Research that spans across the five process orientations calls into question the traditional building blocks of organizational space. Specifically, process studies challenge the underlying assumption that physical structures and measurable distance determine space. The barriers, displays, and hierarchies linked to workplace arrangements and spatial scales are unable to account for the dynamics of organizational space in contemporary work. Rather than focusing on these building blocks, process studies point to four alternative key constructs: movement, boundaries, assemblage, and scaling (see Figure 1). These constructs, derived from their frequent use in process studies of organizational space, are not just core to changes in spacing but also to organizing. In the following, we elaborate on these constructs in detail.

\section{Movement}

Aligned with change, movement is a foundational construct of organizational space. It refers to the actions, practices, events, episodes, flows, trajectories and performances that create, maintain, and transform space. Movement crosses weak and strong process perspectives and is described differently depending on the different process orientations to space and organizing. From a weak process perspective, movement comprises organizational members' actions and interactions within, across, between, or outside preexisting spaces. Movement entails people traversing into new working spaces that can alter patterns of interactions (Nilsson \& Mattes, 2015) and transform how work is performed (Baldry \& Barnes, 2012). Conversely, moving in-between spaces, such as corridors, cars, and garages, creates episodic (Courpasson et al., 2017), event-based (Sturdy et al., 2006), and fleeting experiences (Vesala \& Tuomivaara, 2018) that function as temporary retreats. What is consistent across the weak process orientations is that movement focuses on the uses and modifications of spaces that are "already in existence."

By contrast, a strong process perspective treats movement and space as co-constructing each other. In this view, movement creates space and space's infrastructure makes movement possible (Cnossen \& Bencherki, 2019). Movement surfaces as an ongoing 
FIGURE 1

Key Constructs of Organizational Space as Process

\section{Movement}

The ongoing flows, trajectories, and shifts that enact changes.

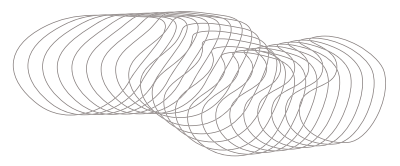

\section{Boundary}

The material and temporal demarcations of space among

individuals, groups, and organizations.

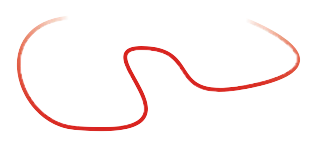

Assemblage

The configuration of human actors, practices, and material

features characteristic to an organizational space.

\section{Scaling}

The reach or the extensiveness of a spatial configuration.

stream of actions and interactions that create patterns manifested as flows, rhythms, practices, and trajectories. Researchers trace, for example, the fluid transition of specific activities and spaces that generate strategic episodes (Jarzabkowski et al., 2015). They capture rhythmic variations in activities that invest space with certain meanings, such as startup entrepreneurship (Katila et al., 2019). Through examining aggregated practices, researchers explain how collectives and spaces come together through particular ways of working that endure over time (Alonso González, 2016; Wilhoit \& Kisselburgh, 2015). They also trace the trajectories or trails of unfolding events that produce organizational direction (Crevani, 2018b). Thus, in the orientations that embrace a strong process perspective, movement centers on the production and effects of the ongoing organizing of space. Movement is the basis for conceiving of space as continuous, ongoing, and unfolding in actions and interactions that enact boundaries, assemblages, and scaling.

\section{Boundary}

Movement makes the construct of boundary a dynamic, ongoing process rather than a fixed barrier or border. Boundary, produced through boundary work, refers to the material and temporal demarcations of space among individuals, groups, and organizations (Langley, Lindberg, Mørk, Nicolini, Raviola, \& Walter, 2019). It draws from the building block of physical structure used in the traditional organizational space literature, but it highlights fluid borders rather than fixed partitions and enclosures. Thus, adopting a process lens shifts the emphasis to negotiating boundaries rather than focusing on the presumption of fixed borders (Dumez \& Jeunemaitre, 2010; Panayioutou, 2015). Boundary work actively engages in forming, separating, blurring, and expanding spaces.

Studies of space and boundary work cross weak and strong process orientations included in this review. In weak process studies, boundaries exist "out there" as markers that indicate where an organization's space 
begins and ends. Even though boundaries change and evolve, space remains intact within borders and gains or reduces in size depending on how members use boundaries to mark off, regulate, open and close, and control access to spaces (Cartel et al., 2019; Fleming \& Spicer, 2004; Langley et al., 2019). Changes to boundaries are constructed incrementally and deliberately based on the capabilities of organizational units and the degree to which actors contest the placement of markers (Dumez \& Jeunemaitre, 2010). Thus, in weak process studies, boundary work reorganizes what has previously been inside or outside of an organization (Fleming \& Spicer, 2004), while keeping these organizational spaces relatively stable.

In strong process studies, organizational members jointly constitute space by constructing boundaries that shape what is and what is not part of organizational space. Boundary work creates space by forming separations or spatial distinctions that direct ongoing organizational actions and interactions. Separations occur through physically moving, positioning material artifacts and people (Munro \& Jordan, 2013), and repeating past boundary practices (Hirst, 2011). Boundary work also entails blurring distinctions by softening and merging previously enacted separations and leading to "indeterminate" boundaries that hold the potential for new demarcations. Through these activities, certain practices, materials, people, affects, and discourses are brought together, whereas others are kept apart (Langley et al., 2019). Studies examining boundary work highlight how it forms space (Clegg \& Kornberger, 2006) through shifts in social and material transactions and ambiguity as to where boundaries reside (Sivunen \& Putnam, 2019). These unexpected and unpredictable occurrences are key to understanding space as forming new patterns of organizing and organization.

\section{Assemblage}

Boundary work also occurs through shifts in the assemblage of space. This key construct refers to changing the configurations of human actors, organizing practices, and material features that enact organizational spaces (Beyes \& Steyaert, 2012; Murdoch, 2006). Assemblage resembles workplace arrangements in the historical view of space, but a process perspective focuses on its emergence in forming space. Studies that adopt a weak process perspective treat assemblage as generally stable and thus focus on shifts that occur over time. For example, rearranging the office, implementing furniture upgrades, relocating organizations (Brennan, Chugh,
\& Kline, 2002; Coradi et al., 2015; McElroy \& Morrow, 2010; Sailer, 2011), or traveling to a different site to participate in meetings with new people (Nilsson \& Mattes, 2015) entail new combinations of people and things. Assemblage contributes to opening up spaces through connecting bodies, physical settings, or removing people from dominant areas (Iedema \& Rhodes, 2010; Shortt, 2015; Sturdy et al., 2006; Vesala \& Tuomivaara, 2018).

By contrast, a strong process perspective conceives of assemblage as fluid and continuously changing configurations that shape what space is and how it is structured (Knox et al., 2015; Peltonen, 2011; Skoglund \& Holt, 2020). Researchers examine how various material objects, bodies, and affective experiences connect with others to collectively perform space. This ongoing assembling gives space its unique form, one that is often difficult to control (Jakonen et al., 2017; Michels \& Steyaert, 2017). Scholars also show how technologies mediate assemblage through connecting geographically distant participants in the formation of space (Hydle, 2015). Other scholars focus on the types of relationships in an assemblage and show, for example, how conflicts require alterations in office spaces (Kingma, 2019; Van Marrewijk \& Van den Ende, 2018) or how emotional responses emerge among space users (Biehl, 2019). Thus, spatial assemblages do not exist "out there," rather they emerge through interconnecting an array of human and material elements that often persist through repeating organizational practices over time and settings (Vásquez \& Cooren, 2013). They come into being through connecting multiple actors, forming affect relationships, and shifting the prominence of spatial features.

\section{Scaling}

Assemblages or spatial configurations have scaling, defined as the reach or the extensiveness of space (Massey, 2005; Murdoch, 2006). Scaling as a construct departs from the historical building block of spatial scales by focusing on the dynamic qualities of space, such as activities that scale up or down. A process perspective, then, challenges the notion of scale as predefined and nested in hierarchies of different sizes. Instead, scaling highlights relationships, practices, activities, and flows that expand or shrink the spatial reach over time. This construct also emphasizes how near or far, up or down, and intimate or distant certain social or material elements of space are (Sewell \& Taskin, 2015; Vásquez, 2016; Vásquez \& Cooren, 2013). 
Scaling appears as a key construct in weak and strong process perspectives of space. In weak ones, scaling and space are distinct phenomenon that can influence each other but function separately. For example, the practices of changing scale, irrespective of space, can alter an organization's reach through capital accumulation, regulation, and articulation of discourse (Spicer, 2006; Taylor \& Spicer, 2007). To extend its scale, organizations often create protected spaces, such as temporary experimental settings, where new ways of doing are safeguarded and shared, thereby increasing an organization's reach in incremental and controlled ways (Bucher \& Langley, 2016; Cartel et al., 2019; Reinecke, 2018).

In strong process studies, however, scaling and space are interdependent and become mutually defining. Spaces both expand and shrink in scale depending on the reach of unfolding organizational actions and interactions. Expanding occurs, for example, when communication technologies extend locales (Brown \& O'Hara, 2003; Hislop \& Axtell, 2009), when organizations "scale up" (Cnossen \& Bencherki, 2019), or when corporations acquire or merge (Zeller, 2000). By contrast, organizational scaling shrinks when space reduces through constricting the magnitude and range in which certain organizational activities once operated. From a strong perspective, the scaling of an organization is constantly renegotiated based on the configuring of several shifting factors. For example, Ratner (2019) shows how the spatial jurisdiction of a school principal expands and shrinks depending on the scale of a pupil's misdeeds (e.g., truancy versus bullying and drug dealing), the availability of police, and the public's complaints. Thus, both space and scaling emerge, expand, and shrink amid configuring space.

\section{The Emergences of Organizational Space}

What is characteristic for process studies of organizational space is their focus on movements or activities that produce space and engage in organizing simultaneously. Instead of measuring physical structures, process researchers describe boundary work or the activities that make boundaries by demarcating material and temporal distinctions of space among individuals, groups, and organizations. In place of identifying different types of physical arrangements, scholars examine organizing activities that reconfigure human actors, practices, and material features into assemblages of space. As opposed to limiting analyses to a particular scale, process necessitates a nuance for scaling as the activities that expand or shrink the reach of an organization's spatial configurations over time (see Figure 1).

A shift to studying these spatial activities challenges the idea that space is a fixed container and urges researchers to consider it instead as emergent through the ongoing production of boundaries, assemblage, and scaling. Through unfolding organizational events, spatial activities put the elements of space into new relationships with each other, concurrently constituting space and organizing. All of the key constructs need to be enacted to constitute space; however, one spatial activity (i.e., boundary work, assembling, and scaling actions) might be more dominant or prominent than another at a given moment. Figure 2 depicts the interface of the ongoing spatial activities that enact space. Even though it puts events in a sequential order, they typically occur simultaneously and can be separate and disconnected events. In effect, the events are not cumulative nor evolutional; they represent how the key constructs and spatial activities come together to constitute space at a given moment in time.

In Figure 2, Box A emphasizes the spatial activity of boundary work. In the movement from Event 1 to Event 2, new boundary work activities exert influence in constituting space. Because this boundary work incorporates different configurations of practices, people, and material artifacts than in Event 1, the spatial activities of assembling and scaling actions also change as part of boundary work negotiations. To illustrate, Vaccaro and Palazzo (2015) examined how boundary work as a dominant spatial activity triggered different patterns of assembling and scaling actions. They showed how a group of anti-Mafia activists used boundary work negotiations, such as including some actors and excluding others, to form a heterogeneous coalition of "powerless actors" that shrunk the scaling operations of the Mafia, for example, their wide-spread practices of paying protection money.

Box B portrays assembling as a dominant activity. Assembling activities configure spatial relations among human actors, material features, and organizational practices. When assembling is the most pervasive activity, configurations shape boundary work and scaling actions. Event 3 shows how new assembling activities form configurations that shape boundary work and scaling actions. Hardy and Maguire (2010) demonstrated how the colocation of heterogeneous actors and material features configured multiple organizational spaces that altered boundary work and scaling actions. 
FIGURE 2

Emergences of Organizational Space Over Time

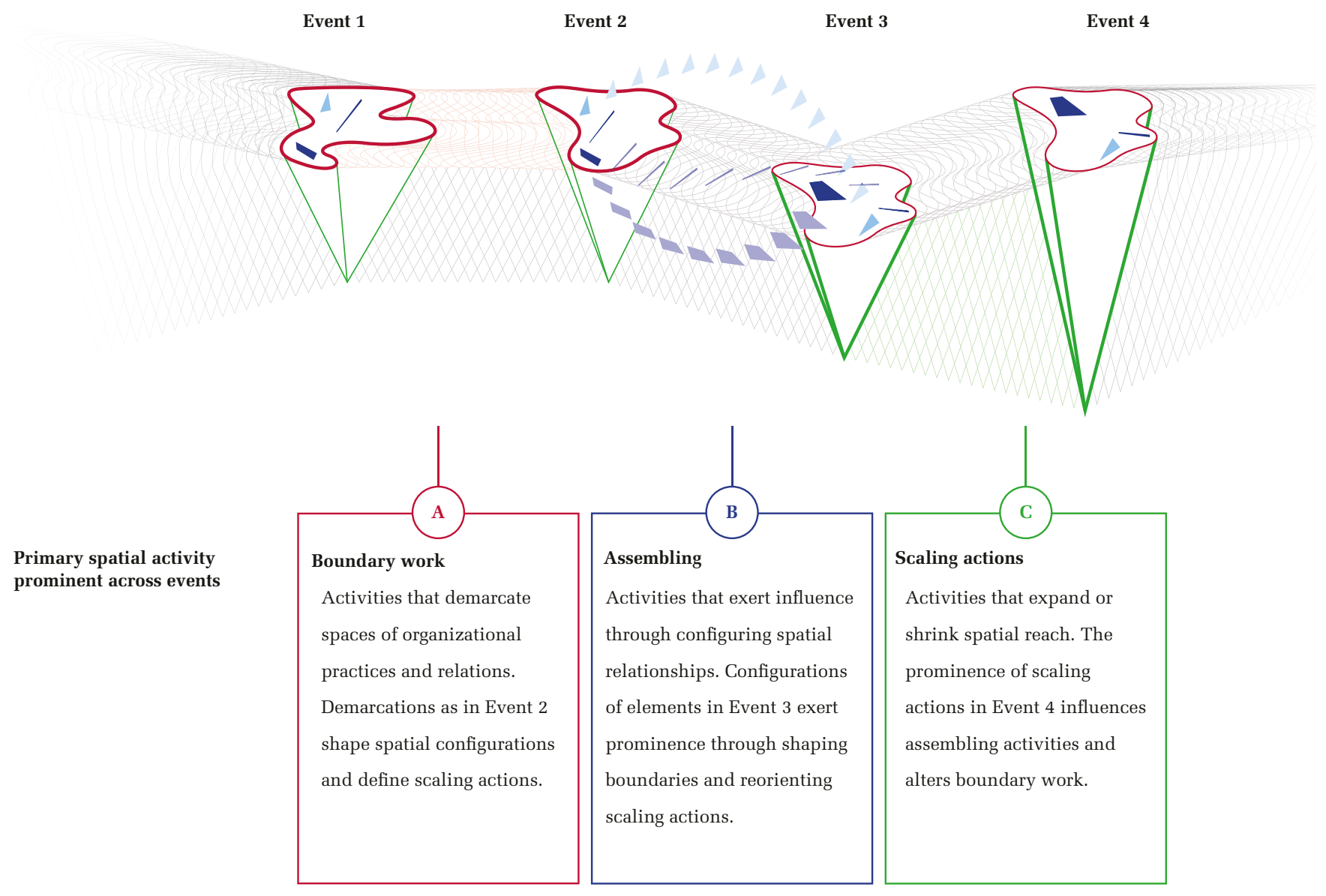

This configuration forged close collaborations across different organizations and altered the scale of particular organizational activities.

Box C accentuates scaling actions that expand/ reduce or extend/shrink the influence of organizational space. As the reach of space changes, so does boundary work and assembling activities. For example, Papazu and Nelund (2018) showed how the scaling actions of an orchard's sustainable practices shrunk space when managers refused to adapt agricultural practices to organic regulations required for the national organic goods network. In doing so, the orchard was excluded from the network (boundary work) "confining them" (assembling) to "a more peripheral existence” (p. 262).

An awareness of how these spatial activities interact to bring the key constructs of organizational space into being provides firm grounding for a processual view. In what follows, we discuss some key features (see Figure 3) that researchers should keep in mind when doing future research on organizational space as process.

\section{DISCUSSION AND DIRECTIONS FOR FUTURE RESEARCH}

This review focuses on process studies of space published in the organizational and management literature. It shows how authors build on five conceptually distinct orientations to examine space: developing, transitioning, imbricating, becoming, and constituting. Developing studies foreground space as a physical setting that changes over time in phases, stages, or episodes, for example, through renovations, repurposing, and spatial rearrangements. These changes introduce new behaviors and interaction patterns among organizational members. Transitioning studies examine how people inhabit new spaces that are in-between or outside the formal organization. These new spaces foster alternative 


\section{FIGURE 3}

\section{Central Observations for Future Research on Organizational Space as Process}

Central Observations

Organizational space is not a pre-existent static container, it is performative in the sense that it comes into being through ongoing events.

1. Through events, movement intersects with other constructs to enact spatial activities as new relationships that constitute space and organizing.

2. To constitute space, all these spatial activities need to be in play; however, one might be more dominant than another in enacting space for a given event or time.

3. Space always has a physicality. It is a hybrid phenomenon made of multiple actors that are both human and material.

ways of organizing that move beyond established rules and norms. Imbricating studies focus on how individuals invest space with significance in day-today practices. The role of space in organizational phenomena, thus, depends on the practices in which it is enacted. Becoming studies treat space as perpetual movement through bodily rhythms, flow, and affects. These studies show how space is qualitatively different in every moment and how it enacts changes in organizing. Finally, constituting studies consider how the social, symbolic, and material elements of space are constantly ordered in relation to each other. This ordering brings space into being and makes organizations durable.

Through developing this typology, we contribute to process research on organizational space by deciphering what space is and how it organizes. This typology also adds coherence to a line of research that has thus far seemed scattered and unsystematic. In depicting how researchers use different process orientations, we show why moving away from a container view requires adopting new analytic constructs to study organizational space, namely, movement, boundary, assemblage, and scaling. In the remainder of this section, we draw on this review to discuss three observations that underlie process studies of organizational space. In discussing them, we suggest key opportunities for future process studies of space.

\section{Space as Organizing}

A first and central observation from this review is that organizational space needs to be organized and that spatial activities function as a form of organizing. First, studies in this review show how space needs to be organized, for example, through renovations and modifications (e.g., McElroy \& Morrow, 2010); day-to-day appropriations and disappropriations (e.g., de Vaujany \& Vaast, 2014); or flows of interaction among humans, technologies, and material artifacts (e.g., Vásquez, 2016). The studies that embrace transitioning, imbricating, becoming, and constituting orientations illustrate how everyday work activities organize space as a mundane ongoing accomplishment.

Second, this review reveals how space itself enacts organizing through what it is "doing," how it does it, and what this means for organizational members. To illustrate, process studies show how space connects, separates, and sorts workers (e.g., Dale, 2005); encourages and discourages particular behaviors (e.g., Fayard \& Weeks, 2007); assigns tasks and activities (e.g., Tyler \& Cohen, 2010); and facilitates resistance among organizational members (e.g., Courpasson et al., 2017). Yet, the ways in which space enacts organizing to produce these practices remain unclear. Thus, process studies of organizational space rarely foreground space as organizing; consequently, we know relatively little about how space shapes organization.

To address this empirical gap, scholars need to study the "spatial activities" that simultaneously enact space and organizing, that is, researchers need to inventory and categorize these activities and center on what they do. Specifically, scholars might investigate boundary work performances, assembling activities that bring multiple social and material elements together, and scaling actions that extend or shrink organizational reach. For example, Rodner, Roulet, Kerrigan, and Vom Lehn (2019) identify blurring and marking as activities vital to the boundary work of artists and the government who vied for controlling Venezuela's Art World. Oittinen (2018), in turn, shows how the linking and arranging of embodied actions, such as gaze, hand gestures, and body positions, organize meeting spaces that both enable and constrain common understandings. Finally, Sewell and Taskin (2015) demonstrate how staff members use telework activities as scaling actions by extending the reach of organizations into homes and simultaneously shrinking nonworking spaces.

Research that focuses on spatial activities demonstrates how space and organizing are intricately 
interconnected (Cnossen \& Bencherki, 2019; Mengis et al., 2019). This work sheds new light on a variety of topics in organizational studies, such as institutional work. The traditional research on space and institutions typically viewed physical buildings as "strong material anchors" that maintained institutions (Monteiro \& Nicolini, 2014: 4). Future research, however, might adopt a process orientation to examine the spatial activities through which this maintenance occurs. To illustrate, Kellogg (2009) shows how boundary work fosters different types of spaces that lead to divergent conditions for institutional change. Similarly, Hardy and Maguire (2010) demonstrate how certain physical spaces (e.g., corridors, plenary sessions, and virtual spaces) colocate combinations of actors and institutional discourses into assembling activities that contest dominant institutional orders. These discourses eventually scale-up to change an institutional field (scaling actions).

In addition to institutional work, examining spatial activities can help researchers uncover new forms of organizational control and resistance. Research on this topic has typically treated space as a physical container that either enabled or constrained organizational control, specifically, how factories, offices, and other physical spaces served as forms of managerial surveillance and control (Baldry, 1997; Dale \& Burrell, 2008). However, when work occurs everywhere, traditional notions of space as containers are less effective in exerting control or enacting resistance. Techniques, such as remote monitoring and algorithmic management, extend control and resistance into homes and public spaces, typically beyond the purview of physical office buildings. Examining boundary work and scaling actions could help researchers understand these techniques as types of spatial activities. Specifically, online meetings and flex work can blur boundary work, such as marking oneself online when a worker is temporarily absent or engaged in multitasking (Richardson \& McKenna, 2014). Scaling actions also extend the reach of local control/resistance through "scaling up" or making spatial activities indirectly applicable to global contexts. For example, work allocation algorithms enact spatial constraints by allowing only a few managers to oversee thousands of geographically dispersed workers, such as Uber and Deliveroo drivers. Reconceptualizing space as process then becomes essential to understanding how control and resistance surface in new forms of organizing.

To build theory on how space organizes, future studies need to develop a lexicon or a common taxonomy of the concepts aligned with process views of organizational space. Even though process studies of space have grown in the past decade, as previously noted, they are widely diffused, highly variable, and not well integrated. Specifically, scholars often draw on a surfeit of concepts imported from other literatures rather than building on existing work. For example, researchers examine concepts such as "time space" (Hydle, 2015), "social space" (Sewell \& Taskin, 2015), "relational space" (Hirst \& Humphreys, 2013), "hybrid workspace" (Munro \& Jordan, 2013), "liminal space" (Shortt, 2015), "identity space” (Daskalaki, Butler, \& Petrovic, 2016), and "heterotopia" (Beyes \& Michels, 2011), often without tying them to existing literature on the same ideas. As a result, research has become fragmented, idiosyncratic, and sometimes isolated from organizations and organizing.

Disagreements regarding the definitions of space and place also confound knowledge in this area. As such, scholars often skirt theoretical assumptions about what space is, what it does, and how it contributes to organizing (Beyes \& Steyaert, 2012; Van Marrewijk \& Yanow, 2010). These issues point to the need for a common, theoretically-rooted taxonomy that encompasses multiple process approaches to organizational space. This taxonomy could aid in theory building and help scholars classify research findings, distinguish among approaches, and consolidate knowledge about key constructs. The process orientations, key constructs, and spatial activities that emanate from this review lay the groundwork for developing this common taxonomy.

\section{Space as Performative}

Closely related to organizing, a second observation that stems from this review is that space is performative and thus, ripe with possibilities. A process view of space means that work and organizing come into being concomitantly rather than sequentially in predefined buildings, streets, and locations (Gregson \& Rose, 2000). In effect, creating, maintaining, and transforming space occurs through the complex ways in which spatial activities perform. To illustrate, transitioning studies highlight how spatial interventions performatively create new conditions for innovations through assembling language, human interactions, and material artifacts, such as walls, windows, and furniture (e.g., Beyes \& Michels, 2011; Furnari, 2014). Imbricating studies focus on how these elements become entangled in the production of space (e.g., Pöyhönen, 2018) and becoming studies 
examine how these elements and spatial activities affect each other (e.g., Beyes \& Steyaert, 2012). Constituting studies illustrate how assemblages and networks perform to give space sense and significance (e.g., Hirst \& Humphreys, 2013).

Focusing on performativity could help researchers examine the dialectics of conceived, perceived, and lived space (Lefebvre, 1991) as ongoing activities rather than as spatial products. In this way, it could reanimate Lefebvrian scholarship through treating the three spatial types as ongoing performances (see also Beyes \& Steyaert, 2012). For example, the spatial activity of assembling could help scholars examine how conceived space (e.g., architectural discourses and designs) becomes entangled with perceived space (e.g., meanings and experiential perceptions of space users) and with lived space (e.g., embodied practices and routines in using space) in changing organizational forms. Researchers could also study how individuals organize particular elements of conceived, perceived, and lived spaces into performative configurations and work environments, such as a "well-functioning workspace." In this way, scholars could use constructs that animate organizational space and, thus, enrich Lefebvrian studies.

In addition, researchers need to conduct additional studies on how the social and material elements of space become intermingled. Although process studies of space have moved in this direction (Knox et al., 2015, 2008; Vásquez, 2016; Wilhoit, 2018), scholars continue to privilege the social over the material elements; hence, future studies need to embrace sociomateriality in a more complete way. Sociomateriality (Orlikowski, 2007) refers to the dynamic and interconnected ways that material elements, such as walls, artifacts, and technologies, become enmeshed in human activity in the production of space, for example, in work transformations. Investigators then might examine how workers in the so-called "gig economy," use spatial activities to assemble social and material platforms, organizations, clients, and artifacts (such as transportation vehicles, mobile phones, algorithms, and digital mechanisms) that enact transitory workspaces.

\section{Production of Space and Agency}

A third observation that emerges from this review is that organizational space and agency are intertwined. Specifically, treating space as a process of organizing invites scholars to focus on the agency of space itself, not just how agents produce space. First, several studies in this review show how individuals and groups exercise agency by organizing space in particular ways (e.g., Beyes \& Michels, 2011; Shortt, 2015), for example, in terms of status (Zhang \& Spicer, 2014) or gender (e.g., Hirst \& Schwabenland, 2018). Second, studies that examine how space itself exercises agency (e.g., Cnossen \& Bencherki, 2019; Vásquez \& Cooren, 2013) move away from a deterministic, causal view between spatial arrangements and human behavior. Instead, the relationships between space and organizational actors underlie the conditions that enable or constrain possible actions. To illustrate, studies in the becoming and the constituting orientations treat agency as a hybrid of multiple human and material actors rather than strictly a human property (e.g., Knox et al., 2015; Vásquez, 2016). Thus, the agency of space stems from the configurations among these multiple human and material agents.

Drawing from these orientations, future research on the agency of space could focus on the dynamic interconnections among individuals and technology in producing contemporary working spaces. Even though traditional studies view space as intimately intertwined with technology (e.g., Brown \& O’Hara, 2003; Hislop \& Axtell, 2009; Knox et al., 2015; Nilsson \& Mattes, 2015), the literature typically casts this relationship as static, for example, studying monitoring systems (Barnes, 2007) and copy machines (Fayard \& Weeks, 2007) as stable factors that shape organizational practices. However, process studies reveal how technologies assemble people and artifacts in coworking spaces (Fabbri, 2016; Jakonen et al. 2017), shape organizing in semipublic spaces such as airports (Knox et al. 2008), and transform physical spaces into dynamic activity systems through virtual work (Sivunen \& Putnam, 2019).

Future research could center on the spatial activities of particular technologies, such as smartphones, laptops, and network infrastructures that exert agency to expand or shrink organizational scale. They could also show how mobile devices interact with shifting locations to reconstitute space throughout the day. Examining what technology does in boundary work could show how Wi-Fi connections transform public and private areas into workspaces and blur boundaries between work and life. Moreover, scholars could study how traditional technologies, such as bells, memo boards (Fabbri, 2016), and external displays (Jakonen et al., 2017), exert agencies through creating assemblages that foster new types of organization. Advanced technologies, such as enterprise social media systems and collaboration tools, also exert agency through extending scaling actions across 
organizational sites, countries, and continents (Ellison, Gibbs, \& Weber, 2015). Thus, focusing on agency by drawing on key constructs developed in this review aids in deciphering how workspaces emerge across different sites and locations-at home, coffee shops, and on the go.

\section{Methodological Challenges and Opportunities}

These suggestions for future research call for innovative methods and techniques to capture spatial activities such as boundary work, assembling multiple social and material elements, and enacting scaling. Even though ethnographic methods play an important role in organizational space research, scholars have not realized the full potential of "spatial ethnography." Specifically, studying space as a process entails complementing conventional observation-based approaches with other ethnographic methods that capture unfolding movements, such as auto-ethnographic (Cunliffe, 2011) and shadowing (Czarniawska, 2014). Video ethnography (LeBaron, Jarzabkowski, Pratt, \& Fetzer, 2018) offers precision in investigating the detailed processes of boundary work and assembling, and global ethnography (Jarzabkowski, Bednarek, \& Cabantous, 2015) aids in exploring scaling actions as organizations extend and reduce their reach.

In general, any research project needs to both "zoom in and out" (Nicolini, 2009), that is, it should focus on the situated, micro-level enactments of space as well as the broad consequences of its production. To illustrate, Best and Hindmarsh (2018) use video-recorded interactions in museums to examine how the micro-level behaviors of tour guides enact macro-level organizational spaces. Also, Munro and Jordan (2013) use mobile ethnography to track the micro-level tactics of street artists at the Edinburgh Festival Fringe. Through charting their moves and countermoves, the authors show how street artists create temporary workspaces that challenge the city's dominant spatial order. Both studies rely on objects, sounds, and actions to trace the processual nature of space and to decipher the in situ practices of organizing. Moreover, these studies demonstrate how process scholars who study space can capture the "aha" moments that surface in the mundane, day-to-day activities of organizing (Jarzabkowski, Lê, \& Spee, 2017). Overall, future studies need to use creative methodological approaches to capture what space is and does and how it performs organizing.

\section{CONCLUSION}

This article synthesizes and integrates process research on organizational space. As such, it reveals the diversity of theoretical approaches that scholars use, the key constructs that they privilege, and the spatial activities that emerge from these investigations. Despite and partly because of these developments, process research on organizational space is widely dispersed, incommensurable, and sometimes disconnected from organizations and organizing.

To address these issues and foster theory building, we suggest that future studies draw on a common, theoretically-rooted taxonomy, one that promotes systematic research and avoids ideological silos. To advance this goal, this article sets forth a typology, key constructs, and spatial activities grounded in the study of organizational space as process. It shows how these constructs cross different process orientations and how they relate to each other. These constructs also form a rubric for developing organization theory in future research.

In addition, by making organizational space the figure or central foci of research, scholars can develop novel ideas to advance investigations of institutional work, control and resistance, and technology. The complexity of contemporary organizational life in which boundaries are fluid, people and technologies are entangled, and the spatial reach of organizations continually grows calls for conceptual and theoretical sophistication to understand space. Using a common taxonomy that encompasses multiple approaches has the potential to enrich process research on organizations writ large as well as on space.

\section{REFERENCES}

Allen, M., \& Brown, S. D. 2016. Memorial meshwork: The making of the commemorative space of the Hyde Park 7/7 Memorial. Organization, 23(1): 10-28.

Allen, T. J. 1977. Managing the flow of technology. Cambridge, MA: MIT Press.

Alonso González, P. 2016. The organization of commemorative space in postcolonial Cuba: From Civic Square to Square of the Revolution. Organization, 24(1): 47-70.

Amin, A., \& Cohendet, P. 2004. Architectures of knowledge: Firms, capabilities, and communities. Oxford: Oxford University Press.

Amin, A., Massey, D., \& Thrift, N. 2003. Decentering the nation: A radical approach to regional inequality. London: Catalyst.

Augé, M. 1995. Non-places: Introduction to an anthropology of supermodernity. London: Verso. 
Bain, P., \& Taylor, P. 2000. Entrapped by the 'electronic panopticon'? Worker resistance in the call centre. New Technology, Work and Employment, 15(1): 2-18.

Bakken, T., \& Hernes, T. 2006. Organizing is both a verb and a noun: Weick meets Whitehead. Organization Studies, 27(11): 1599-1616.

Baldry, C. 1997. The social construction of office space. International Labour Review, 136(3): 365-378.

Baldry, C. 1999. Space-the final frontier. Sociology, 33(3): $535-553$.

Baldry, C., \& Barnes, A. 2012. The open-plan academy: Space, control and the undermining of professional identity. Work, Employment \& Society, 26(2): 228-245.

Bar-Lev, S., \& Vitner, G. 2011. Performing a crisis: Institutional politics and the construction of (ir)responsibility. Organization, 19(6): 667-684.

Barnes, A. 2007. The construction of control: The physical environment and the development of resistance and accommodation within call centres. New Technology, Work and Employment, 22(3): 246-259.

Bazin, Y., \& Naccache, P. 2016. The emergence of heterotopia as a heuristic concept to study organization. European Management Review, 13(3): 225-233.

Berg, P. O., \& Kreiner, K. 1990. Corporate architecture: Turning physical settings into symbolic resources. In P. Gagliardi (Ed.), Symbols and artifacts. New York: Aldine de Gruyter.

Berti, M., Simpson, A., \& Clegg, S. 2018. Making a place out of space: The social imaginaries and realities of a Business School as a designed space. Management Learning, 49(2): 168-186.

Best, K., \& Hindmarsh, J. 2018. Embodied spatial practices and everyday organization: The work of tour guides and their audiences. Human Relations, 72(2): 248-271.

Beyes, T. 2010. Uncontained: The art and politics of reconfiguring urban space. Culture and Organization, 16(3): 229-246.

Beyes, T., \& Michels, C. 2011. The production of educational space: Heterotopia and the business university. Management Learning, 42(5): 521-536.

Beyes, T., \& Steyaert, C. 2012. Spacing organization: Nonrepresentational theory and performing organizational space. Organization, 19(1): 45-61.

Biehl, B. 2019. "In the mix": Relational leadership explored through an analysis of techno DJs and dancers. Leadership, 15(3): 339-359.

Biehl-Missal, B. 2016. Filling the "empty space”: Sitespecific dance in a techno club. Culture and Organization, 25(1): 16-31.
Boon, B. 2007. Room attendants in the hotel guest room space. Journal of Management and Organization, 13(2): 160-174.

Borch, C. 2009. Organizational atmospheres: Foam, affect and architecture. Organization, 17(2): 223-241.

Bourdieu, P. 1977. Outline of a theory of pratice. Cambridge, UK: Cambridge University Press.

Brennan, A., Chugh, J., \& Kline, T. 2002. Traditional versus open office design: A longitudinal field study. Environment and Behavior, 34(3): 279-299.

Brown, B., \& O’Hara, K. 2003. Place as a practical concern of mobile workers. Environment and Planning $\boldsymbol{A}$, 35(9): 1565-1587.

Bucher, S., \& Langley, A. 2016. The interplay of reflective and experimental spaces in interrupting and reorienting routine dynamics. Organization Science, 27(3): 594-613.

Burrell, G., \& Dale, K. 2014. Space and organization studies. In P.Adler, P.du Gay, G.Morgan, \& M.Reed (Eds.), The Oxford handbook of sociology, social theory, and organization studies. Oxford: Oxford University Press.

Cairns, G. 2002. Aesthetics, morality and power: Design as espoused freedom and implicit control. Human Relations, 55(7): 799-820.

Cairns, G., McInnes, P., \& Roberts, P. 2003. Organizational space/time: From imperfect panoptical to heterotopian understanding. Ephemera, 3(2): 126-139.

Callahan, J. 2013. Space, the final frontier? Social movements as organizing spaces for applying HRD. Human Resource Development International, 16(3): 298-312.

Callon, M., \& Law, J. 2004. Introduction: AbsencePresence, circulation, and encountering in complex space. Environment and Planning D: Society and Space, 22(1): 3-11.

Carmona, S., Ezzamel, M., \& Gutiérrez, F. 1997. Control and cost accounting practices in the Spanish Royal Tobacco factory. Accounting, Organizations and Society, 22(5): 411-446.

Cartel, M., Boxenbaum, E., \& Aggeri, F. 2019. Just for fun! How experimental spaces stimulate innovation in institutionalized fields. Organization Studies, 40(1): 65-92.

Chinitz, B. 1961. Contrasts in agglomeration: New York and Pittsburgh. American Economic Association, 51(2): 279-289.

Clegg, S., Cunha, M., \& Rego, A. 2012. The theory and practice of utopia in a total institution: The pineapple panopticon. Organization Studies, 33(12): 1735-1757.

Clegg, S., \& Kornberger, M. (Eds.). 2006. Organizing space. Space, organizations and management theory. Oslo, Norway: Liber \& Copenhagen Business School Press. 
Cnossen, B., \& Bencherki, N. 2019. The role of space in the emergence and endurance of organizing: How independent workers and material assemblages constitute organizations. Human Relations, 72(6): 1057-1080.

Cohen, R. 2010. Rethinking 'mobile work': Boundaries of space, time and social relation in the working lives of mobile hairstylists. Work, Employment and Society, 24(1): 65-84.

Cooren, F. 2006. The organizational world as a plenum of agencies. Communication as organizing: Empirical and theoretical approaches to the dynamic of text and conversation. Mahwah, NJ: Erlbaum.

Cooren, F., \& Fairhurst, G. 2004. Speech timing and spacing: The phenomenon of organizational closure. Organization, 11(6): 793-824.

Cooren, F., Fox, S., Robichaud, D., \& Talih, N. 2005. Arguments for a plurified view of the social world: Spacing and timing as hybrid achievements. Time $\mathcal{E}$ Society, 14(2-3): 265-282.

Coradi, A., Heinzen, M., \& Boutellier, R. 2015. A longitudinal study of workspace design for knowledge exploration and exploitation in the research and development process. Creativity \& Innovation Management, 24(1): 55-71.

Costas, J. 2013. Problematizing mobility: A metaphor of stickiness, non-places and the kinetic elite. Organization Studies, 34(10): 1467-1485.

Courpasson, D., Dany, F., \& Delbridge, R. 2017. Politics of place: The meaningfulness of resisting places. Human Relations, 70(2): 237-259.

Crevani, L. 2018a. Is there leadership in a fluid world? Exploring the ongoing production of direction in organizing. Leadership, 14(1): 83-109.

Crevani, L. 2018b. Privilege in place: How organisational practices contribute to meshing privilege in place. Scandinavian Journal of Management, 35(2): 101035.

Cunliffe, A. L. 2011. Crafting qualitative research: Morgan and Smircich 30 years on. Organizational Research Methods, 14(4): 647-673.

Cunliffe, A. L., \& Luchman, J. T. 2013. Key concepts in organization theory. Thousand Oaks, CA: Sage Publications Ltd.

Czarniawska, B. 2004. On time, space, and action nets. Organization, 11(6): 773-791.

Czarniawska, B. 2014. Observation on the move: Shadowing. In B. Czarniawska (Ed.), Social science research: From field to desk: 43-56. Los Angeles, CA: Sage.

Dale, K. 2005. Building a social materiality: Spatial and embodied politics in organizational control. Organization, 12(5): 649-678.
Dale, K., \& Burrell, G. 2008. The spaces of organisation and the organization of space: Power, identity and materiality at work. Basingstoke, UK: Palgrave MacMillan.

Dashtipour, P., \& Rumens, N. 2018. Entrepreneurship, incongruence and affect: Drawing insights from a Swedish anti-racist organisation. Organization, 25(2): 223-241.

Daskalaki, M., Butler, C. L., \& Petrovic, J. 2016. Somewhere in-between : Narratives of place, identity, and translocal work. Journal of Management Inquiry, 25(2): 184-198.

Daskalaki, M., \& Kokkinidis, G. 2017. Organizing solidarity initiatives: A socio-spatial conceptualization of resistance. Organization Studies, 38(9): 1303-1325.

Daskalaki M., Stara A., \& Imas, M. 2008. The "parkour organisation": Inhabitation of corporate spaces. Culture and Organization, 14(1): 49-64.

Davis, T. R. V. 1984. The influence of the physical environment in offices. The Academy of Management Reveiw, 9(2): 271-283.

Decker, S. 2014. Solid intentions: An archival ethnography of corporate architecture and organizational remembering. Organization, 21(4): 514-542.

de Certeau, M. 1984. The practice of everyday life. Berkley, MI: University of California Press.

Deleuze, G., \& Guattari, F. 1987. A thousand plateaus: Capitalism and schizophrenia, vol. 2. London: Athlone.

Derksen, K., Blomme, R., de Caluwé, L., Rupert, J., \& Simons, R. 2019. Breaking the paradox: Understanding how teams create developmental space. Journal of Management Inquiry, 28(3): 366-380.

de Vaujany, F., \& Vaast, E. 2014. If these walls could talk: The mutual construction of organizational space and legitimacy. Organization Science, 25(3): 713-731.

D’Mello, M., \& Sahay, S. 2007. "I am kind of a nomad where I have to go places and places"... Understanding mobility, place and identity in global software work from India. Information and Organization, 17(3): 162-192.

Dobson, S. 2012. Characterizing the evolution of commercial organizational spaces. International Journal of Organizational Analysis, 20(3): 309-322.

Dumez, H., \& Jeunemaitre, A. 2010. The management of organizational boundaries: A case study. M@n@ gement, 13(3): 152.

Ellison, N. B., Gibbs, J. L., \& Weber, M. S. 2015. The use of enterprise social network sites for knowledge sharing in distributed organizations: The role of organizational affordances. American Behavioral Scientist, 59(1): 103-123.

Elmholdt, K., Clausen, R., \& Madsen, M. 2018. Seductive atmospheres: Using tools to effectuate spaces for 
leadership development. Journal of Change Management, 18(4): 257-280.

Elsbach, K. D., \& Pratt, M. G. 2007. The physical environment in organizations. The Academy of Management Annals, 1(1): 181-224.

Ernst, J. 2017. Between change and reproduction: Profession, practice and organizational space in a hospital department. Journal of Organizational Ethnography, 6(3): 177-189.

Evans, S., \& Boyte, H. 1986. Free spaces: The sources of democratic change in America. New York: Harper \& Row.

Fabbri, J. 2016. "Place as spatio-temporal events": Empirical evidence from everyday life in a coworking space. M@n@gement, 19(4): 353-361.

Fahy, K., Easterby-Smith, M., \& Lervik, J. E. 2014. The power of spatial and temporal orderings in organizational learning. Management Learning, 45(2): 123-144.

Fayard, A., \& Weeks, J. 2007. Photocopiers and watercoolers: The affordances of informal interaction. Organization Studies, 28(5): 605-634.

Fleming, P., \& Spicer, A. 2004. "You can checkout anytime, but you can never leave": Spatial boundaries in a high commitment organization. Human Relations, 57(1): 75-94.

Foucault, M. 1977. Discipline and punish: the birth of the prison. London: Penguin Books.

Foucault, M. 1986. Of other spaces. Diacritics, 16(1): 22-27.

Furnari, S. 2014. Interstitial spaces: Microinteraction settings and the genesis of new practices between institutional fields. Academy of Management Review, 39(4): 439-462.

Gagliardi, P. 1990. Symbols and artifacts: Views of the corporate landscape. New York: Aldine de Gruyter.

Gander, J. M. 2015. Situating creative production: recording studios and the making of a pop song. Management Decision, 53(4): 843-856.

Gibson, J. 1986. The ecological approach to visual perception. Hillsdale, NJ: Lawrence Erlbaum Associates.

Giddens, A. 1984. The constitution of society: Elements of the theory of structuration. Berkley, CA: University of California Press.

Gieryn, T. F. 2000. A space for place in sociology. Annual Review of Sociology, 26(May): 463-496.

Giovannoni, E., \& Quattrone, P. 2018. The materiality of absence: Organizing and the case of the incomplete cathedral. Organization Studies, 39(7): 849-871.
Graumann, C. 1976. The concept of appropriation (aneignung) and modes of appropriation of space. In P. Korosec-Serfaty (Ed.), Appropriation of space: 113-125. Strasbourg, France: Louis Pasteur University.

Greenhalgh, T., \& Peacock, R. 2005. Effectiveness and efficiency of search methods in systematic reviews of complex evidence: Audit of primary sources. British Management Journal, 331(7524): 1064-1065.

Gregson, N., \& Rose, G. 2000. Taking butler elsewhere: Performativities, spatialities and subjectivities. Environment and Planning D: Society and Space, 18(4): 433-452.

Halford, S. 2008. Sociologies of space, work and organisation: From fragments to spatial theory. Sociology Compass, 2(3): 925-943.

Halford, S., \& Leonard, P. 2005. Place, space and time: Contextualizing workplace subjectivities. Organization Studies, 27(5): 657-676.

Hancock, P., \& Spicer, A. 2011. Academic architecture and the constitution of the new model worker. Culture and Organization, 9551(November): 91-105.

Hardy, C., \& Maguire, S. 2010. Discourse, fieldconfiguring events, and change in organizations and institutional fields: Narratives of DDT and the Stockholm convention. Academy of Management Journal, 53(6): 1365-1392.

Harvey, D. 1990. Between space and time: Reflections on the geographical imagination. Annals of the Association of American Geographers, 80(3): 418-434.

Hatch, M. J. 1987. Physical barriers, task characteristics, and interaction activity in research and development firms. Administrative Science Quarterly, 32(3): 387-399.

Hatch, M. J., \& Cunliffe, A. L. 2013. Organization theory: Modern, symbolic, and postmodern perspectives (3rd ed.). Oxford: Oxford University Press.

Helin, J., Hernes, T., Hjorth, D., \& Holt, R. (Eds.). 2014. The Oxford handbook of process philosophy and organization studies. Oxford: Oxford University Press.

Hernes, T. 2014. A process theory of organization. Oxford: Oxford University Press.

Hernes, T., Bakken, T., \& Olsen, P. I. 2006. Spaces as process: Developing a recursive perspective on organizational space. In S. R.Clegg, \& M.Kornberger (Eds.), Space, organization, and management theory. Oslo, Norway: Liber and Copenhagen Business School Press.

Herod, A., Rainnie, A., \& McGrath-Champ, S. 2007. Working space: Why incorporating the geographical is central to theorizing work and employment practices. Work, Employment \& Society, 21(2): 247-264.

Hirst, A. 2011. Settlers, vagrants and mutual indifference: Unintended consequences of hot-desking. 
Journal of Organizational Change Management, 24(6): 767-788.

Hirst, A., \& Humphreys, M. 2013. Putting power in its place: The centrality of edgelands. Organization Studies, 34(10): 1505-1527.

Hirst, A., \& Schwabenland, C. 2018. Doing gender in the 'new office'. Gender, Work \& Organization, 25(2): 159-176.

Hislop, D., \& Axtell, C. 2009. To infinity and beyond?: Workspace and the multi-location worker. New Technology, Work and Employment, 24(1): 60-75.

Hjorth, D. 2005. Organizational entrepreneurship with de Certeau on creating heterotopias (or spaces for play). Journal of Management Inquiry, 14(4): 386-398.

Hoskin, K. 2004. Spacing, timing and the invention of management. Organization, 11(6): 743-757.

Howard-Grenville, J., Golden-Biddle, K., Irwin, J., \& Mao, J. 2011. Liminality as cultural process for cultural change. Organization Science, 22(2): 522-539.

Hua, Y., Loftness, V., Kraut, R., \& Powell, K. M. 2010. Workplace collaborative space layout typology and occupant perception of collaboration environment. Environment and Planning B: Planning and Design, 37(3): 429-448.

Husted, E., \& Plesner, U. 2017. Spaces of open-source politics: Physical and digital conditions for political organization. Organization, 24(5): 648-670.

Hydle, K. 2015. Temporal and spatial dimensions of strategizing. Organization Studies, 36(5): 643-663.

Iedema, R., \& Carroll, K. 2011. The “clinalyst” Institutionalizing reflexive space to realize safety and flexible systematization in health care. Journal of Organizational Change Management, 24(2): 175-190.

Iedema, R., \& Rhodes, C. 2010. The undecided space of ethics in organizational surveillance. Organization Studies, 31(2): 199-217.

Iedema, R., Rhodes, C., \& Scheers, H. 2006. Surveillance, resistance, observance: Exploring the teleo-affective volatility of workplace interaction. Organization Studies, 27(8): 1111-1130.

Jakonen, M., Kivinen, N., Salovaara, P., \& Hirkman, P. 2017. Towards an economy of encounters? A critical study of affectual assemblages in coworking. Scandinavian Journal of Management, 33(4): 235-242.

Jansen, R. 2008. Jurassic technology? Sustaining presumptions of intersubjectivity in a disruptive environment. Theory and Society, 37(2): 127-159.

Jarzabkowski, P., Bednarek, R., \& Cabantous, L. 2015. Conducting global team-based ethnography: Methodological challenges and practical methods. Human Relations, 68(1): 3-33.
Jarzabkowski, P., Burke, G., \& Spee, P. 2015. Constructing spaces for strategic work: A multimodal perspective. British Journal of Management, 26(S1): S26-S47.

Jarzabkowski, P., Lê, J., \& Spee, P. 2017. Taking a strong process approach to analyzing qualitative process data: 237-253. The Sage Handbook of Process Organization Studies. London: Sage Publications Ltd.

Jewell, L. N., \& Reitz, H. J. 1981. Group effectiveness in organizations. Glenview, IL: Scott Foresman.

Jones, D. 2014. Restorative counter-spacing for academic sustainability. Organization $\&$ Environment, 27(3): 297-314.

Jones, D. 2018. Could slow be beautiful? Academic counter-spacing within and beyond "the slow swimming club." Journal of Management Inquiry, 27(4): 420-435.

Jones, G., McLean, C., \& Quattrone, P. 2004. Spacing and timing. Organization, 11(6): 723-741.

Katila, S., Kuismin, A., \& Valtonen, A. 2019. Becoming upbeat: Learning the affecto-rhythmic order of organizational practices. Human Relations, doi: 10.1177/ 0018726719867753.

Kellogg, K. 2009. Operating room: Relational spaces and microinstitutional change in surgery. American Journal of Sociology, 115(3): 657-711.

Kelly, M. P. 1980. White-collar proletariat: The industrial behaviour of British civil servants. London: Routledge.

Khazanchi, S., Sprinkle, T. A., Masterson, S. S., \& Tong, N. 2018. A spatial model of work relationships: The relationship-building and relationship-straining effects of workspace design. Academy of Management Review, 43(4): 590-609.

Kingma, S. F. 2016. The constitution of 'third workspaces' in between the home and the corporate office. New Technology, Work and Employment, 31(2): 176-193.

Kingma, S. 2019. New ways of working (NWW): Work space and cultural change in virtualizing organizations. Culture and Organization, 25(5): 383-406.

Kingma, S., Dale, K., \& Wasserman, V. 2018. Organizational space and beyond: The significance of Henri Lefebvre for organisation studies. New York: Routledge.

Knox, H., O’Doherty, D., Vurdubakis, T., \& Westrup, C. 2007. Rites of passage: Organization as an excess of flows. Scandinavian Journal of Management, 23(3): 265-284.

Knox, H., O’Doherty, D., Vurdubakis, T., \& Westrup, C. 2008. Enacting airports: Space, movement and modes of ordering. Organization, 15(6): 869-888.

Knox, H., O’Doherty, D., Vurdubakis, T., \& Westrup, C. 2015. Something happened: Spectres of organization/ 
disorganization at the airport. Human Relations, 68(6): 1001-1020.

Kociatkiewicz, J., \& Kostera, M. 2011. Transitional space. Tamara: Journal for Critical Organization Inquiry, 9(3-4): 7-9.

Kociatkiewicz, J., \& Kostera, M. 2015. Into the labyrinth: Tales of organizational nomadism. Organization Studies, 36(1): 55-71.

Komporozos-Athanasiou, A., Thompson, M., Fotkai, M. 2018. Performing accountability in health research: A socio-spatial framework. Human Relations, 71(9): 1264-1287.

Kornberger, M., \& Clegg, S. 2003. The architecture of complexity. Culture and Organization, 9(2): 75-91.

Kornberger, M., \& Clegg, S. 2004. Bringing space back in: Organizing the generative building. Organization Studies, 25(7): 1095-1114.

Küpers, W. 2015. Emplaced and embodied mobility in organizations. Ephemera, 15(4): 797-823.

Lancione, M., \& Clegg, S. 2013. The chronotopes of change: Actor-networks in a changing business school. Journal of Change Management, 13(2): 117-142.

Langley, A. 1999. Strategies for theorizing from process data. The Academy of Management Review, 24(4): 691.

Langley, A. 2007. Process thinking in strategic organization. Strategic Organization, 5(3): 271-282.

Langley, A., Lindberg, K., Mørk, B. E., Nicolini, D., Raviola, E., \& Walter, L. 2019. Boundary work among groups, occupations and organizations: From cartography to process. Academy of Management Annals, 13(2): 704-736.

Langley A., Smallman C., Tsoukas H., \& Van de Ven, A. 2013. Process studies of change in organization and management: Unveiling temporality, activity, and flow. Academy of Management Journal, 56(1): 1-13.

Langley, A., \& Tsoukas, H. (Eds.). 2017. The Sage handbook of process organization studies. Thousand Oaks, CA: Sage.

Larsen, J., \& Schultz, M. 1990. Artifacts in a bureaucratic monastery. Symbols and Artifacts: Views of the Corporate Landscape, 281: 302.

Latour, B. 1993. We have never been modern. London: Harvester Wheatsheaf.

Latour, B. 2005. Reassembling the social-An introduction to actor-network-theory. Oxford: Oxford University Press.

Law, J. 1994. Organizing modernity. Oxford: Blackwell.

LeBaron, C., Jarzabkowski, P., Pratt, M., \& Fetzer, G. 2018. An introduction to video methods in organizational research. Organizational Research Methods, 21(2): 239-260.
Lee, M. Y., Mazmanian, M. A., \& Perlow, L. 2020. Fostering positive relational dynamics in teams: The power of spaces and interaction scripts. Academy of Management Journal, 63(1): 96-123.

Lefebvre, H. 1991. The production of space. Oxford: Blackwell.

Leitner, H. 1997. Reconfiguring the spatiality of power: The construction of a supranational migration framework for the European Union. Political Geography, 16(2): 123-143.

Leonardi, P. M. 2011. When flexible routines meet flexible technologies: Affordance, constraint, and the imbrication of human and material agencies. MIS Quarterly, 35(1): 147-167.

Leonardi, P. M., \& Barley, S. R. 2010. What's under construction here? Social action, materiality, and power in constructivist studies of technology and organizing. The Academy of Management Annals, 4(1): 1-51.

Lewis, P. 2008. Emotion work and emotion space: Using a spatial perspective to explore the challenging of masculine emotion management practices. British Journal of Management, 19(s1): s120-s140.

Liu, Y., \& Grey, C. 2017. History, gendered space and organizational identity: An archival study of a university building. Human Relations, 71(5): 640-667.

Lucas, M. 2014. "Nomadic" organization and the experience of journeying: Through liminal spaces and organizing places. Culture and Organization, 20(3): 196-214.

Maaninen-Olsson, E., \& Müllern, T. 2009. A contextual understanding of projects: The importance of space and time. Scandinavian Journal of Management, 25(3): 327-339.

Mair, J., \& Hehenberger, L. 2014. Front-stage and backstage convening: The transition from opposition to mutualistic coexistence in organizational philanthropy. Academic of Management Journal, 57(4): 1174-1200.

Massey, D. 2005. For space. London: Sage Publications Ltd.

Maréchal, G., Linstead, S., \& Munro, I. 2013. The territorial organization: History, divergence and possibilities. Culture and Organization, 19(3): 185-208.

McElroy, J., \& Morrow, P. 2010. Employee reactions to office redesign: A naturally occurring quasi-field experiment in a multi-generational setting. Human Relations, 63(5): 609-636.

McNulty, T., \& Stewart, A. 2015. Developing the governance space: A study of the role and potential of the company secretary in and around the board of directors. Organization Studies, 36(4): 513-535. 
Mengis, J., Nicolini, D., \& Gorli, M. 2016. The video production of space: How different recording practices matter. Organizational Research Methods, 21(2): 288-315.

Michaud, V. 2014. Mediating the paradoxes of organizational governance through numbers. Organization Studies, 35(1): 75-101.

Michels, C., \& Steyaert, C. 2017. By accident and by design: Composing affective atmospheres in an urban art intervention. Organization, 24(1): 79-104.

Molli, F., Mengis, J., \& van Marrewijk, A. 2019. The aestheticization of hybrid space: The atmosphere of the Locarno Film Festival. Organization Studies, doi: 10.1177/0170840619867348.

Monge, P. R., \& Kenneth, K. 1980. Measuring proximity in human organization. Social Psychology Quarterly, 43(1): 110-115.

Monteiro, P., \& Nicolini, D. 2015. Recovering materiality in institutional work: Prizes as an assemblage of human and material entities. Journal of Management Inquiry, 24(1): 61-81.

Muller, E., \& Morgan, J. 1962. Location decision of manufacturers. The American Economic Review, 52(2): 204-217.

Munro, R. 2018. Creativity, organisation and entrepreneurship: Power and play in the ecological press of money. Organization Studies, 39(2-3): 209-227.

Munro, I., \& Jordan, S. 2013. "Living space" at the Edinburgh festival fringe: Spatial tactics and the politics of smooth space. Human Relations, 66(11): 1497-1525.

Murdoch, J. 2006. Postmodernist geography. London: Sage Publications.

Nash, L. 2018. Gendered places: Place, performativity and flânerie in the city of London. Gender, Work and Organization, 25: 601-620.

Nash, L. 2020. Performing place: A Rhythmanalysis of the city of London. Organization Studies, 41(3): 301-321.

Nicolini, D. 2009. Zooming in and out: Studying practices by switching theoretical lenses and trailing connections. Organization Studies, 30(12): 1391-1418.

Nilsson, M., \& Mattes, J. 2015. The spatiality of trust: Factors influencing the creation of trust and the role of face-to-face contacts. European Management Journal, 33(4): 230-244.

Oldham, G., \& Brass, D. 1979. Employee reactions to an open-plan office: A naturally occurring quasi-experiment. Administrative Science Quarterly, 24(2): 267284.

Oldham, G. R., \& Fried, Y. 1987. Employee reactions to work-space characteristics. Journal of Applied Psychology, 72: 75-80.
Oldham, G. R., \& Rotchford, N. L. (1983). Relationships between office characteristics and employee reactions: A study of the physical environment. Administrative Science Quarterly, 28(4): 542-556.

Olins, W. 1978. The corporate personality: An inquiry into the nature of corporate identity. London: Design Council.

Oittinen, T. 2018. Multimodal accomplishment of alignment and affiliation in the local space of distant meetings. Culture and Organization, 24(1): 31-53.

Ometto, M., Gegenhuber, T., Winter, J., \& Greenwood, R. 2019. From balancing missions to mission drift: The role of the institutional context, spaces, and compartmentalization in the scaling of social enterprises. Business \& Society, 58(5): 1003-1046.

O'Reilly, D., Allen, S., \& Reedy, P. 2018. Reimagining the scales, dimensions and fields of socio-ecological sustainability. British Journal of Management, 29(2): 220-234.

Orlikowski, W. J. 2007. Sociomaterial practices: Exploring technology at work. Organization Studies, 28(9): 14351448.

Orlikowski, W. J., \& Yates, J. 2002. It’s about time: Temporal structuring in organizations. Organization Science, 13(6): 684-700.

Panayiotou, A. 2015. Spacing gender, gendering space: A radical "strong plot" in film. Management Learning, 46(4): 427-443.

Papazu, I., \& Nelund, M. 2018. Scaling as an organizational method: Ethnographic explorations of two Danish sustainability organizations. British Journal of Management, 29(2): 252-265.

Paquette J., \& Lacassagne, A. 2013. Subterranean subalterns: Territorialisation, deterritorialisation, and the aesthetics of mining. Culture and Organization, 19(3): 242-260.

Peltonen, T. 2011. Multiple architectures and the production of organizational space in a Finnish university. Journal of Organizational Change Management, 24(6): 806-821.

Peltonen, T. 2012. Exploring organizational architecture and space: a case for heterodox research. International Journal of Organizational Analysis, 20(1): 68-81.

Pelz, D. C., \& Andrews, F. M. 1966. Scientists in organizations: Productive climates for research and development. New York: Wiley.

Perkmann, M., Mckelvey, M., \& Phillips, N. 2019. Protecting scientists from Gordon Gekko: How organizations use hybrid spaces to engage with multiple institutional logics. Organization Science, 30(2): 298-318. 
Petani, F., \& Mengis, J. 2016. In search of lost space: The process of space planning through remembering and history. Organization, 23(1): 71-89.

Polletta, F. 1999. "Free spaces" in collective action. Theory and Society, 28(1): 1-38.

Pöyhönen, S. 2018. Room for communitas: Exploring sociomaterial construction of leadership in liminal and dominant spaces. Leadership, 14(5): 585-599.

Rao, H., \& Dutta, S. 2012. Free spaces as organizational weapons of the weak: Religious festivals and regimental mutinies in the 1857 Bengal Native Army. Administrative Science Quarterly, 57(4): 625-668.

Ratner, H. 2019. Topologies of organization: Space in continuous deformation. Organization Studies, doi: 10.1177/0170840619874464.

Raulet-Croset, N. \& Borzeix, A. 2014. Researching spatial practices through Commentated Walks: "on the move" and "walking with." Journal of Organizational Ethnography, 3(1): 27-42.

Reinecke, J. 2018. Social movements and prefigurative organizing: Confronting entrenched inequalities in Occupy London. Organization Studies, 39(9): 1299-1321.

Riach, K., \& Wilson, F. 2014. Bodyspace at the pub: Sexual orientations and organizational space. Organization, 21(3): 329-345.

Richardson, J., \& McKenna, S. 2014. Reordering spatial and social relations: A case study of professional and managerial flexworkers. British Journal of Management, 25(4): 724-736.

Rodgers, D. M., Petersen, J., \& Sanderson, J. 2016. Commemorating alternative organizations and marginalized spaces: The case of forgotten Finntowns. Organization, 23(1): 90-113.

Rodner, V., Roulet, T. J., Kerrigan, F., \& Vom Lehn, D. 2019. Making space for art: A spatial perspective of disruptive and defensive institutional work in Venezuela's art world. Academy of Management Journal, doi: 10.5465/amj.2016.1030.

Ropo, A., \& Höykinpuro, R. 2017. Narrating organizational spaces. Journal of Organizational Change Management, 30(3): 357-366.

Ropo, A., \& Salovaara, P. 2019. Spacing leadership as an embodied and performative process. Leadership, 15(4): 461-479.

Ropo, A., Sauer, E., \& Salovaara, P. 2013. Embodiment of leadership through material place. Leadership, 9(3): 378-395.

Sage, D., Justesen, L., Dainty, A., Tryggestad, K., \& Mouritsen, J. 2016. Organizing space and time through relational human-animal boundary work: Exclusion, invitation and disturbance. Organization, 23(3): 434-450.

Sailer, K. 2011. Creativity as social and spatial process. Facilities, 29(1/2): 6-18.

Saunders, C., Rutkowski, A. F., van Genuchten, M., Vogel, D., \& Molina Orrego, J. 2011. Virtual space and place: Theory and test. MIS Quarterly, 35(4): 1079-1098.

Sergot, B., \& Saives, A. L. 2016. Unplugged-relating place to organization: A situated tribute to Doreen Massey. M@n@gement, 19(4): 335-352.

Sewell, G., \& Taskin, L. 2015. Out of sight, out of mind in a new world of work? Autonomy, control, and spatiotemporal scaling in telework. Organization Studies, 36(11), 1507-1529.

Sheppard, E., \& McMaster, R. B. 2004. Introduction: Scale and geographic inquiry. In E. Sheppard, \& R. M. McMaster (Eds.), Scale and Geographic Inquiry: 1-22. Oxford: Blackwell.

Shortt, H. 2015. Liminality, space and the importance of 'transitory dwelling places' at work. Human Relations, 68(4): 633-658.

Siebert, S., Wilson, F., \& Hamilton, J. 2017. "Devils may sit here": The role of enchantment in institutional maintenance. Academy of Management Journal, 60(4): 1607-1632.

Simpson. B., Tracey, R., \& Weston, A. 2018. Traveling concepts: Performative movements in learning/playing. Management Learning, 49(3): 295-310.

Sivunen, A., \& Putnam, L. L. 2019. The dialectics of spatial performances: The interplay of tensions in activitybased organizing. Human Relations, doi: 10.1177/ 0018726719899728.

Skogland, M. A. C., \& Hansen, G. K. 2017. Change your space, change your culture: exploring spatial change management strategies. Journal of Corporate Real Estate, 19(2): 95-110.

Skoglund, A., \& Holt, R. 2020. Spatially organizing future genders: An artistic intervention in the creation of a hir-toilet. Human Relations, doi: 10.1177/ 0018726719899728.

Soja, E. W. 1998. Thirdspace: Journeys to Los Angeles and other real-and-imagined places. Capital \& Class, 22(1): 137-139.

Spicer, A. 2006. Beyond the convergence-divergence debate: The role of spatial scales in transforming organizational logic. Organization Studies, 27(10): 1467-1483.

Steyaert, C. 2010. Queering space: Heterotopic life in Derek Jarman's garden. Gender, Work and Organization, 17(1): 45-68.

Strati, A. 1999. Organization and aesthetics. London: Sage. 
Sturdy, A., Schwarz, M., \& Spicer, A. 2006. Guess who’s coming to dinner? Structures and uses of liminality in strategic management consultancy. Human Relations, 59(7): 929-960.

Sundstrom, E., Burt, R. E., \& Kamp, D. 1980. Privacy at work: Architectural correlates of job satisfaction and job performance. The Academy of Management Journal, 23(1): 101-117.

Sundstrom, E., \& Sundstrom M. 1986. Work places: The psychology of the physical environment in offices and factories. Cambridge, UK: Cambridge University Press.

Swyngedouw, E. 1996. Reconstructing citizenship, the rescaling of the state and the new authoritarianism: Closing the Belgian mines. Urban Studies, 33: 1499-1521.

Taylor, F. W. 1911. The principles of scientific management: 202. New York: Harper \& Brothers.

Taylor, S., \& Spicer, A. 2007. Time for space: A narrative review of research on organizational spaces. International Journal of Management Reviews, 9(4): 325346.

Thrift, N. 1999. Steps to an ecology of place. In D. Massey, J. Allen, \& P. Sarre (Eds.), Human Geography Today: 295-322. Cambridge, UK: Polity Press.

Thrift, N. 2008. Non-representational theory. London: Routledge.

Thanem, T. 2010. Free at last? Assembling, producing and organizing sexual spaces in Swedish sex education. Gender, Work and Organization, 17(1): 91-112.

Thanem, T. 2012. All talk and no movement? Homeless coping and resistance to urban planning. Organization, 19(4): 441-460.

Tietze, S. 2005. Discourse as strategic coping resource: Managing the interface between "home" and "work". Journal of Organizational Change Management, 18(1): 48-62.

Tsoukas, H., \& Chia, R. 2002. On organizational becoming: Rethinking organizational on organizational Becoming : Rethinking organizational change. Organization Science, 13(5): 567-582.

Turner, V. 1974. Dramas, fields and metaphors. Ithaca, NY: Cornell University Press.

Tyler, M., \& Cohen, L. 2010. Spaces that matter: Gender performativity and organizational space. Organization Studies, 31(2): 175-198.

Vaccaro, A., \& Palazzo, G. 2015. Values against violence: Institutional change in societies dominated by organized crime. Academy of Management Journal, 58(4): 1075-1101.

Våland, M., \& Georg, S. 2018. Spacing identity: Unfolding social and spatial-material entanglements of identity performance. Scandinavian Journal of Management, 34(2): 193-204.

Van Marrewijk, A. 2009. Corporate headquarters as physical embodiments of organisational change. Journal of Organizational Change Management, 22(3): 290-306.

Van Marrewijk, A. 2011. Aesthetic experiences of designed organisational space. International Journal of Work Organisation and Emotion, 4(1): 61-77.

Van Marrewijk, A., \& Van den Ende, L. 2018. Changing academic work places: The introduction of open-plan offices in universities. Journal of Organizational Change Management, 31(5): 1119-1137.

Van Marrewijk, A., \& Yanow, D. 2010. Introduction the spatial turn in organizational studies. Organizational spaces: Rematerializing the workaday world: 1-16. Cheltenham, UK: Edward Elgar Publishing.

Vásquez, C. 2016. A spatial grammar of organising: Studying the communicative constitution of organisational spaces communicative constitution of organisational spaces. Communication Research and Practice, 2(3): 351-377.

Vásquez, C., Brummans, B., \& Groleau, C. 2012. Notes from the field on organizational shadowing as framing. Qualitative Research in Organizations and Management: An International Journal, 7(2): 144-165.

Vásquez, C., \& Cooren, F. 2013. Spacing practices: The communicative configuration of organizing through space-times. Communication Theory, 23(1): 25-47.

Verduyn, K. 2015. Entrepreneuring and process: A Lefebvrian perspective. International Small Business Journal: Researching Entrepreneurship, 33(6): 638-648.

Vermeulen, J. 2011. The bridge as playground: Organizing sport in public space. Culture and Organization, 17(3): 231-251.

Vesala, H., \& Tuomivaara, S. 2018. Experimenting with work practices in a liminal space: A working period in a rural archipelago. Human Relations, 71(10): 1371-1394.

Vidaillet, B., \& Bousalham, Y. 2020. Coworking spaces as places where economic diversity can be articulated: Towards a theory of syntopia. Organization, 27(1): 60-87.

Waistell, J. 2006. Metaphorical mediation of organizational change across space and time. Journal of Organizational Change Management, 19(5): 640-654.

Wapshott, R., \& Mallett, O. 2011. The spatial implications of homeworking: A Lefebvrian approach to the rewards and challenges of home-based work. Organization, 19(1): 63-79. 
Wasserman, V., \& Frenkel, M. 2011. Organizational aesthetics: Caught between identity regulation and culture jamming. Organization Science, 22(2): 503-521.

Wasserman, V. \& Frenkel, M. 2015. Spatial work in between glass ceilings and glass walls: Gender-class intersectionality and organizational aesthetics. Organization Studies, 36(11): 1485-1505.

Watkins, C. 2005. Representations of space, spatial practices and spaces of representation: An application of Lefebvre's spatial triad. Culture and Organization, 11(3): 209-220.

Weick, K. E. 1974. Amendments to organizational theorizing. Academy of Management Journal, 17(1): 487-502.

Weinfurtner, T., \& Seidl, D. 2019. Towards a spatial perspective: An integrative review of research on organisational space. Scandinavian Journal of Management, 35(2): 1-30.

Wilhoit, E. 2017. "My drive is my sacred time”: Commuting as routine liminality. Culture and Organization, 23(4): 263-276.

Wilhoit, E., \& Kisselburgh, L. 2015. Collective action without organization: The material constitution of bike commuters as collective. Organization Studies, 36(5): 573-592.

Wilhoit, E. D. 2018. Space, place, and the communicative constitution of organizations: A constitutive model of organizational space. Communication Theory, 28(3): 311-331.

Wilner, A., Christopoulous, M., \& Alves, M. 2017. The online unmanaged organization: Control and resistance in a space with blurred boundaries. Journal of Business Ethics, 141(4): 677-691.

Wilson, J., O’Leary, M., Metiu, A., \& Jett, Q. 2008. Perceived proximity in virtual work: Explaining the paradox of far-but-close. Organization Studies, 29(7): 979-1002.

Yeung, H. W. C. 1998. The social-spatial constitution of business organizations: A geographical perspective. Organization, 5(1): 101-128.

Zalesny, M., \& Farace, R. 1987. Traditional versus open offices: A comparison of sociotechnical, social relations, and symbolic meaning perspectives. Academy of Management Journal, 30(2): 240-259.

Zeller, C. 2000. Rescaling power relations between trade unions and corporate management in a globalising pharmaceutical industry: The case of the acquisition of Boehringer Mannheim by Hoffman - La Roche. Environment and Planning A, 32(9): 1545-1567.
Zhang, Z., \& Spicer, A. 2014. "Leader, you first": The everyday production of hierarchical space in a Chinese bureaucracy. Human Relations, 67(6): 739-762.

Zhang, Z., Spicer, A., \& Hancock, P. 2008. Hyperorganizational space in the work of J. G. Ballard. Organization, 15(6): 889-910.

Zietsma, C., \& Lawrence, T. B. 2010. Institutional work in the transformation of an organizational field: The interplay of boundary work and practice work. Administrative Science Quarterly, 55(2): 189-221.

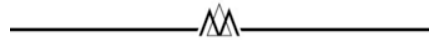

Kathleen A. Stephenson (k.a.stephenson@vu.nl) is an Assistant Professor of Organization Studies with the School of Business and Economics at the Vrije Universiteit Amsterdam, the Netherlands. Her research interests include organizational space, organizational change and maintenance, and power. Her current research examines how individual rhythms and mobility relate to strategic changes and aims.

Ari Kuismin (ari.kuismin@aalto.fi) is a Postdoctoral Researcher at Aalto University School of Business, Finland. His research focuses on changing forms of work and organizing, especially from the perspectives of organizational space, temporality, and politics. His empirical studies are based on ethnographic research methods. He is currently working on projects that deal with employee experience and wellbeing at work.

Linda L. Putnam (lputnam@comm.ucsb.edu) is a Distinguished Research Professor Emerita at the University of California, Santa Barbara. Her research interests include tensions and paradoxes, organizational space, negotiation and conflict management, and discourse studies. She is the co-editor of eleven books, a former Academy of Management Board Member, and a Fellow/Distinguished Scholar of three associations.

Anu Sivunen (anu.e.sivunen@jyu.fi) is a Professor in the Department of Language and Communication Studies at University of Jyväskylä, Finland. Her research focuses on communication technologies and organizational knowledge sharing, global teams and other distributed work arrangements, as well as organizational space. Her work has appeared in journals from a variety of disciplines.

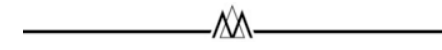

